\title{
Pigmentos y tecnología artística mochicas: una nueva aproximación en la comprensión de la organización social
}

Pigments et technologie artistique mochicas : une nouvelle approche pour comprendre l'organisation sociale Mochica pigments and technology: a new approach for understanding social organization

\section{Véronique Wright}

\section{(2) OpenEdition}

Journals

Edición electrónica

URL: http://journals.openedition.org/bifea/1950

DOI: 10.4000/bifea.1950

ISSN: 2076-5827

Editor

Institut Français d'Études Andines

Edición impresa

Fecha de publicación: 1 agosto 2010

Paginación: 299-330

ISSN: 0303-7495

Referencia electrónica

Véronique Wright, « Pigmentos y tecnología artística mochicas: una nueva aproximación en la comprensión de la organización social », Bulletin de l'Institut français d'études andines [En línea], 39 (2) | 2010, Publicado el 01 febrero 2011, consultado el 10 diciembre 2020. URL : http:// journals.openedition.org/bifea/1950; DOI : https://doi.org/10.4000/bifea.1950

\section{(c) (†) $\odot$}

Les contenus du Bulletin de l'Institut français d'études andines sont mis à disposition selon les termes de la licence Creative Commons Attribution - Pas d'Utilisation Commerciale - Pas de Modification 4.0 International. 


\title{
Pigmentos y tecnología artística mochicas: una nueva aproximación en la comprensión de la organización social
}

\author{
Véronique Wright*
}

\begin{abstract}
Resumen
Para la civilización mochica, el arte mural representaba una expresión artística muy importante que permitía a la élite transmitir al pueblo una codificación simbólica de su propio poder. Por ende, más allá de un rol decorativo, desempeñaba una función de vector ideológico, fundamental para esta sociedad sin escritura textual. La importancia del adorno mural en esta sociedad llevó el autor a estudiar su proceso de elaboración con una herramienta aún poco utilizada: la arqueometría. Desarrollando investigaciones físico químicas sobre la policromía de la huaca de la Luna, de la huaca Cao Viejo, del complejo de Castillo de Huancaco y de la Plataforma funeraria de Sipán, se han podido adquirir datos inéditos en cuanto a la tecnología pictórica y a la identidad de los artesanos pintores mochicas.
\end{abstract}

Palabras clave: mochica, murales, policromía, arqueometría

\section{Pigments et technologie artistique mochicas : une nouvelle approche pour comprendre l'organisation sociale}

\section{Résumé}

Pour la civilisation mochica, I'art mural représentait une expression artistique très importante qui permettait à l'élite de délivrer au peuple une codification symbolique de son propre pouvoir. Cet art n'était donc pas seulement décoratif mais exerçait aussi le rôle de vecteur idéologique, fondamental

* Doctora en Antropología, Etnología, Prehistoria (especialidad: Arqueometría aplicada a la Arqueología Precolombina) por la Universidad Panthéon Sorbonne-Paris 1. Investigadora asociada al Centre de Recherche et de Restauration des Musées de France, C2RMF-Palais du Louvre: Porte des Lions, 14 Quai François Mitterrand - 75001 París. E-mail: vero_wright@hotmail.com Se desempaña actualmente como directora de la Casa Matisse. 
pour cette civilisation sans écriture textuelle. L'importance du décor mural au sein de cette société a donc incité l'auteur à étudier son processus d'élaboration, à l'aide d'un outil peu exploité au Pérou sur ce type de supports : I'archéométrie. Ainsi, grâce à l'étude physico-chimique de la polychromie de la Huaca de la Luna, de la Huaca Cao Viejo, du complexe de Castillo de Huancaco et de la plate-forme funéraire de Sipán, de nouveaux éléments de compréhension ont surgi quant à la technologie picturale et à l'identité des artisans peintres mochicas.

Mots clés : mochica, décor mural, polychromie, archéométrie

\title{
Mochica pigments and technology: a new approach for understanding social organization
}

\begin{abstract}
To the Mochica civilization, mural art represented an important form of artistic expression that allowed the rulers to deliver a symbolic message of established political power to the people. It not only had a decorative function but also a much more symbolic role: one with an ideological vector, essential for a civilization without any textual writing. The importance of mural decoration within Mochica society inspired us to push beyond the previous research, taking an interest in studying the production process of these murals by using a form of archaeometry, rarely employed in Peru. Through the physicochemical study of the polychromy of the Huaca de la Luna, of the Huaca Cao Viejo, of the complex of Castillo de Huancaco, and of the funeral platform of Sipán, we have been able to obtain clues to the Mochica's pictorial techniques and the painters' identity.
\end{abstract}

Key words: Mochica, mural painting, polychromy, archaeometry

\section{INTRODUCCIÓN}

El arte constituye una fuente de entendimiento de la evolución histórica y política de una sociedad. Sin embargo la palabra «arte» es ambigua. Puede corresponder al aspecto técnico del trabajo del artesano o definir a un artista. No es una imitación de la naturaleza ni un reflejo de lo real, sino una transposición, la obra de un hombre que tiene una historia y pertenece a una clase social y a un medio. Por ende, la obra de arte revestirá un «sentido político» (Verguez \& Huisman, 1990). Es evidente que las sociedades precolombinas producían pocas imágenes en comparación con nuestra sociedad. Empero, plasmar algunas de ellas en murales, en particular de monumentos públicos, permitía a estas sociedades utilizarlas como medio privilegiado de comunicación. El pueblo accedía así a temas religiosos que asimilaba y entendía, pues este saber reflejaba la estructura de la existencia que seguía su grupo cultural. Entonces la imagen se convertía en un medio de adoctrinamiento visual (Francastel, 1970). Se volvía más importante que la palabra: material y duradero, se convertía en una sustracción del símbolo al pensamiento abstracto (Otte, 2005). Para la sociedad mochica, que desconocía la escritura textual, el arte y sus varias expresiones adquirían, por eso, una dimensión 
particular. El artista mochica obedece a una cierta cantidad de reglas cuyo aprendizaje se adquiere viviendo en esta cultura (Donnan, 1978). «Impregnado» de éstas, las respetaba y las aplicaba para vehicular un mensaje codificado pero preciso, inteligible por todo el grupo.

\section{EL ARTE MURAL MOCHICA}

Los vestigios de esta expresión artística se encuentran plasmados sobre todo en edificios «sagrados» monumentales, y en los sitios donde se realizaban ceremonias, centro de la autoridad, vinculando entre sí los distintos conceptos de una ideología religiosa precisa. Así, los adornos pintados mochicas están reservados en su mayoría a los edificios rituales o huacas. Estos murales se encuentran pintados sobre las paredes internas y externas de los templos para impactar un público lo más amplio posible.

Los artistas mochicas han utilizado modos de representaciones ancestrales y contemporáneos, pero con reinterpretaciones y adaptaciones singulares del mensaje que querían entregar. Las escenas pintadas sobre los monumentos constituyen un lenguaje narrativo codificado dictado por la clase gobernante. El artista se encuentra entonces al servicio de la élite para transmitir un mensaje al cual adhiere él mismo. Su libertad de creación es limitada, en la medida en la cual utiliza códigos preestablecidos e impuestos por la élite (Morales, 2003). Utiliza también normas para los colores, con una paleta cromática compuesta por cinco colores de base, más o menos saturados y a veces mezclados: rojo, amarillo, negro, azul-gris y el blanco a menudo como color de fondo.

El arte mochica permite así notificar y explicar al pueblo el rol de la élite. Se vuelve un medio de comunicación privilegiado que impacta el subconsciente, transmitiendo un mensaje claro del poder y del orden social. Este discurso ideológico se expresa sin palabras, pero con códigos iconográficos precisos y explícitos que se convierten en un lenguaje (Bawden, 1996). Entonces, los conjuntos arquitectónicos y sus adornos son dedicados al culto a las divinidades y a las ceremonias asociadas.

Vestigios de policromía mural fueron descubiertos sobre todo el territorio mochica. A pesar de la existencia de identidades regionales, los temas iconográficos son muy similares, ilustrando principalmente el panteón mochica, con varias representaciones de la divinidad principal, y el Tema de la Ceremonia de Sacrificio, etapa central de la religión mochica. Las élites de cada valle han adoptado y respetado una ideología común, para mantener una unidad política sobre todo el territorio (regiones sur y norte).

Parece evidente que el artista mochica ha tenido un rol esencial en el seno de esta sociedad. En ese sentido aprehender este artista debería permitir adquirir nuevas informaciones sobre la organización social mochica. Gracias a un estudio arqueométrico intentaremos responder a varias preguntas: ¿Quién era este artista? ¿Cómo realizaba los murales? ¿Con qué materiales? ¿Qué fue su estatus social? ¿Cómo se organizaba su clase artesanal? 


\section{LAS PROBLEMÁTICAS DE INVESTIGACIÓN}

\section{1. Los aportes de la arqueometría}

El estudio de los relieves y de las pinturas murales mochicas consiste a menudo en un enfoque estilístico o iconográfico pero la caracterización físico química, así como el estudio tecnológico de estos vestigios, siguen muy escasos. Algo paradójico si consideramos la quantidad de informaciones inéditas que nos brinda una investigación arqueométrica sobre los materiales empleados y las técnicas artísticas.

En efecto, estas experimentaciones analíticas constituyen un método de investigación muy eficaz, que nos permite entender las diferentes etapas de realización de un mural. Podemos obtener informaciones sobre los materiales empleados para las capas pictóricas, sobre la composición y la preparación del soporte, sobre el origen de los materiales y sobre las herramientas necesarias a la realización de un mural. Así podemos reconstituir la «cadena operativa» seguida por los artistas pintores, desde la extracción de las materias primas hasta la conclusión del mural, o sea la «tecnología artística». Sin embargo, a pesar de su interés y de sus aportes, este tipo de investigación arqueométrica permanece aún poco utilizado para los murales precolombinos, y más precisamente mochicas.

\section{2. Los primeros análisis sobre los pigmentos mochicas}

Los primeros análisis físico químicos sobre murales mochicas permitieron adquirir información sobre las mezclas pictóricas (fig. 1). El elemento colorante corresponde a un pigmento, generalmente, de origen mineral. El único pigmento orgánico es fabricado con carbón de madera de especie indeterminada, caracterizado en los sitios de La Mina y El Brujo (fig. 2) (Bonavia, 1985; Franco et al., 1994; Kakoulli, 1997; Sabana \& Reyna, 1998; Bourgès, 1998; Scott et al., 1998; Wright, 2002; 2005). Sin embargo, estas investigaciones involucran, en cada caso, pocas muestras lo que no permite comprobar su veracidad y la representatividad de los resultados obtenidos. Se concentraron sobre la caracterización de las capas pictóricas, aunque los soportes permanecieron poco estudiados. Además, el protocolo experimental de laboratorio desarrollado era muy limitado y divergía según las investigaciones. La procedencia de los materiales permanecia indeterminada aunque sea interesante constatar que los artesanos ceramistas o tejedores de la huaca de la Luna habrían explotado fuentes de arcillas locales (Chapdelaine et al., 1995; 2001).

La idea del añadido de productos orgánicos, de tipo aglutinante, es una simple conjetura, pues ningún análisis pudo caracterizarlo químicamente. Los datos bibliográficos y etnológicos permiten sin embargo sugerir el uso de sustancias de origen vegetal y animal (Petersen, 1970; Bonavia, 1985; Uceda \& Tufinio, 2003; comunicaciones personales de Pedro Azabache y Julio Urbina, 2006). 
Pigmentos y tecnología artística mochicas: nueva aproximación para comprender la organización social

\begin{tabular}{|c|c|c|c|c|c|c|c|}
\hline Región & \multicolumn{3}{|c|}{ Mochica Norte } & \multicolumn{4}{|c|}{ Mochica Sur } \\
\hline Valle & La Leche & $\begin{array}{c}\text { Lamba- } \\
\text { yeque }\end{array}$ & $\begin{array}{l}\text { Jequete- } \\
\text { peque }\end{array}$ & Chicama & Moche & Virú & Nepeña \\
\hline Sitio & $\begin{array}{c}\text { La } \\
\text { Mayanga }\end{array}$ & Sipán & La Mina & $\begin{array}{c}\text { El Brujo } \\
\text { Huaca Cao } \\
\text { Viejo }\end{array}$ & $\begin{array}{c}\text { Moche } \\
\text { Huaca de la } \\
\text { Luna }\end{array}$ & $\begin{array}{l}\text { Castillo de } \\
\text { Huancaco }\end{array}$ & Pañamarca \\
\hline Rojo & cinabrio & hematita & $\begin{array}{l}\text { ocre rojo } \\
\text { + calcita }\end{array}$ & hematita & hematita & $\begin{array}{l}\text { hematita } y / o \\
\text { cinabrio }\end{array}$ & $\begin{array}{l}\text { calcita } \\
+ \\
\text { hematita }\end{array}$ \\
\hline Amarillo & $\begin{array}{l}\text { goetita + } \\
\text { limonita }\end{array}$ & goetita & $\begin{array}{l}\text { ocre } \\
\text { amarillo }\end{array}$ & goetita & goetita & goetita & $\begin{array}{l}\text { calcita } \\
+ \\
\text { hematita } \\
+ \text { limonita }\end{array}$ \\
\hline Blanco & $\mathrm{cal}$ & arcillas & calcita & $\begin{array}{l}\text { calcita } \\
+ \text { arcilla }\end{array}$ & $\begin{array}{l}\text { arcilla } \\
\text { (caolinita } \\
+ \text { ilita) }\end{array}$ & $\begin{array}{l}\text { calcita } \\
+ \text { arcilla }\end{array}$ & $\begin{array}{l}\text { calcita } \\
+ \text { limonita }\end{array}$ \\
\hline Gris & & $\begin{array}{l}\text { carbón de } \\
\text { madera } \\
\text { + calcita } \\
\text { + goetita } \\
\text { + } \\
\text { hematita }\end{array}$ & $\begin{array}{l}\text { carbón de } \\
\text { madera } \\
\text { + calcita }\end{array}$ & $\begin{array}{l}\text { carbón de } \\
\text { madera } \\
\text { + calcita } \\
\text { + arcilla }\end{array}$ & $\begin{array}{l}\text { carbón de } \\
\text { madera } \\
+ \text { arcilla } \\
\text { (caolinita } \\
+ \text { ilita) }\end{array}$ & $\begin{array}{l}\text { carbón de } \\
\text { madera } \\
\text { + calcita } \\
\text { + arcilla }\end{array}$ & $\begin{array}{l}\text { calcita } \\
+ \\
\text { magnetita }\end{array}$ \\
\hline Negro & pirolusita & $\begin{array}{l}\text { carbón de } \\
\text { madera }\end{array}$ & $\begin{array}{l}\text { carbón de } \\
\text { madera }\end{array}$ & $\begin{array}{l}\text { carbón de } \\
\text { madera }\end{array}$ & $\begin{array}{l}\text { carbón de } \\
\text { madera }\end{array}$ & & $\begin{array}{l}\text { calcita } \\
+ \\
\text { magnetita }\end{array}$ \\
\hline Verde & & & crisocola & & (malaquita & $\begin{array}{l}\text { malaquita } \\
+ \text { atacamita }\end{array}$ & \\
\hline Morado & & $\begin{array}{l}\text { carbón de } \\
\text { madera + } \\
\text { hematita }\end{array}$ & & & & & \\
\hline Carga & & $\begin{array}{l}\text { yeso y/o } \\
\text { calcita }\end{array}$ & calcita? & $\begin{array}{l}\text { yeso y/o } \\
\text { calcita }\end{array}$ & $\begin{array}{l}\text { yeso y/o } \\
\text { calcita }\end{array}$ & $\begin{array}{l}\text { yeso y/o } \\
\text { calcita }\end{array}$ & calcita? \\
\hline Aglutinante & & & & $\begin{array}{l}\text { cola } \\
\text { proteínica } \\
+ \text { San } \\
\text { Pedro }\end{array}$ & $\begin{array}{l}\text { cola } \\
\text { proteínica } \\
+ \text { San Pedro }\end{array}$ & $\begin{array}{l}\text { aglutinante } \\
\text { proteínico } \\
+?\end{array}$ & \\
\hline
\end{tabular}

Figura 1 - Cuadro recapitulativo de todos los datos analíticos adquiridos sobre los murales mochicas

En itálico son indicados los estudios anteriores y en negrita los sitios analizados en el marco de nuestra investigación. Permite exponer la composición de las mezclas colorantes, precisando el elemento colorante, y los coadyuvantes.

Algunas observaciones permitieron obtener indicios sobre las técnicas de preparación del soporte. El muro de adobe habría sido alisado con un enlucido o revoque, sobre el cual se habrían plasmado los diseños con incisiones. De realizar una pintura, el artista habría aplicado un fondo blanco y en seguida los colores, en función de las zonas delimitadas. Si ejecutó un relieve, habría modelado los volúmenes con barro, sobre los cuales habría puesto el fondo blanco y luego los colores (Schaedel, 1951; Bonavia, 1985; Franco et al., 1994; 2003; Campana \& Morales, 1997).

Los vestigios de herramientas utilizadas en la elaboración de murales moches son excepcionales. Solamente siete artefactos identificados como manos de moler fueron descubiertos en la Plataforma Uhle de Moche (Morales, 2000b). La utilización de broqueles o pinceles se limita a hipótesis propuestas gracias a comparaciones con artefactos Chimús o Incas, puesto que ninguna herramienta similar fue descubierta en contexto mochica. 


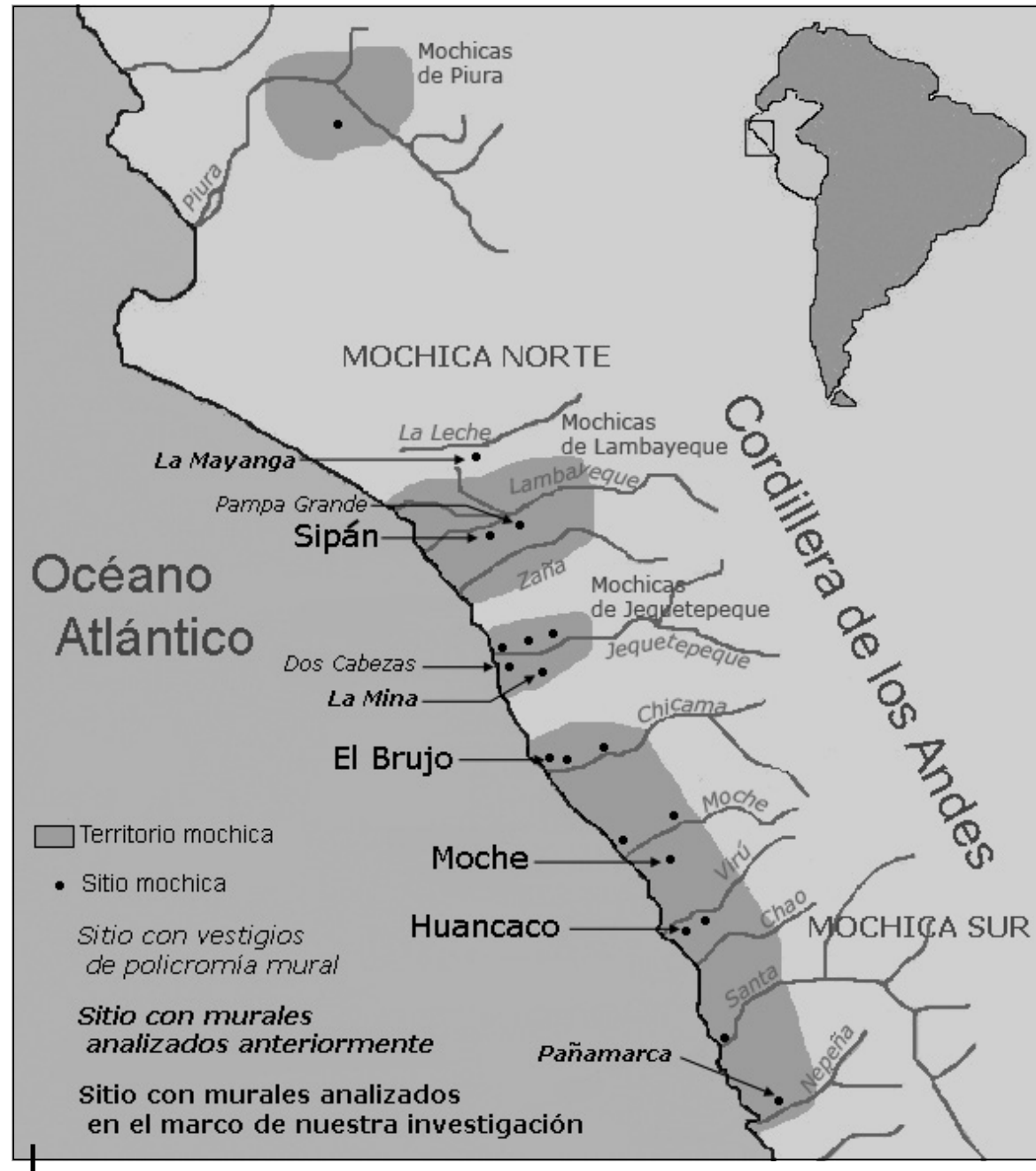

Figura 2 - Mapa de la costa norte del Perú que permite ubicar el territorio mochica, los sitios mochicas catalogados, los que traen vestigios de policromía mural, cuyos murales fueron analizados anteriormente, así como los que han sido estudiados en el marco de nuestra investigación

Wright, 2009 según el modelo de Castillo \& Uceda, ms.

Estos primeros estudios aportan pocos datos sobre la cadena operativa seguida por los artesanos pintores. Sin embargo podemos identificar varias actividades distintas: la extracción de las materias primas, la preparación de los pigmentos y de las mezclas colorantes, la preparación de los soportes, la realización de los diseños, y la aplicación de la pintura sobre las superficies preparadas.

Por eso es importante entender la organización y la repartición de estas tareas entre los artesanos pintores. ¿Fueron los mismos artesanos quienes extrajeron los pigmentos, prepararon el muro soporte y aplicaron la pintura? ¿Cuál ha sido 
el estatus social de cada uno y su relación con la élite? Para intentar responder a estas interrogaciones vamos a proseguir con los análisis preliminares sobre los sitios de la huaca de la Luna, en el sitio de Moche en el mismo valle de Moche, de la huaca Cao Viejo en el complejo El Brujo en el valle de Chicama, de Castillo de Huancaco en el valle de Virú y luego de Sipán en el valle de Lambayeque (fig. 2). El número de muestras es representativo y corresponde a un área cronológica bastante amplia. Además, con un protocolo experimental completo podremos trabajar sobre la caracterización de los materiales minerales y su procedencia, pero también sobre los productos orgánicos. Cruzar los resultados adquiridos y los datos bibliográficos nos permitirá seguir la historia de las técnicas artísticas empleadas en un sitio particular y sobre todo el territorio, y entender la evolución en el espacio y el tiempo de la tecnología pictórica mochica.

\section{LOS SITIOS ESTUDIADOS}

Los vestigios de policromía sobre la huaca de la Luna, sitio central de nuestra investigación, corresponden a pinturas y relieves encontrados sobre los edificios E, D, B/C y A y la Plataforma III, ocupados del $3^{\text {er }}$ al $8^{\text {vo }}$ siglo d. C. El muestrario que hemos realizado, en estrecha colaboración con el Proyecto Arqueológico Huaca de la Luna (PAHL), comprende muestras de murales de cada fase o sea 140 fragmentos pintados que corresponden a cinco siglos de ocupación continua.

El segundo edificio decorado estudiado es la huaca Cao Viejo, en el sitio El Brujo en el valle de Chicama, ocupado del principio de nuestra era al $7^{\mathrm{mo}}$ siglo d. C. Ahí pudimos trabajar sobre los murales de dos fases constructivas diferentes: los Edificios $E$ y $D$ ocupados del principio de nuestra era al $3^{\text {er }-4}{ }^{\text {to }}$ siglo d. C., de los cuales hemos sacado quince muestras.

Finalmente, en la región Mochica Sur, hemos analizado los vestigios descubiertos en el complejo monumental de Castillo de Huancaco, en el valle de Virú. Los rasgos de policromía consisten en pinturas policromas, de las cuales hemos sacado nueve muestras, fechadas por radiocarbón sobre las estructuras asociadas, entre el $7^{\text {mo }}$ y el $8^{\text {vo }}$ siglo d. C. (Bourget, 2003).

Luego, el estudio arqueométrico fue ampliado a la región Mochica Norte, con el análisis de los adornos descubiertos sobre la plataforma funeraria, o Huaca III, de Sipán en el valle de Lambayeque (Alva, 2004). Hemos estudiado siete muestras de los fragmentos policromos descubiertos sobre la última fase constructiva de este edificio, ocupada hasta el $7^{\circ}$ siglo d. C. (Roque et al., 2002).

En el marco de nuestra investigación, hemos sacado 161 muestras de murales policromos, provenientes de cuatro centros administrativos mayores mochicas (fig. 2). Cubriendo todo el territorio y un área cronológica suficientemente amplia, podemos caracterizar la evolución espacio-temporal de la tecnología artística mochica. Por otra parte, cruzando los datos obtenidos, podremos entender las conexiones establecidas entre cada sitio y cada región y más generalmente las relaciones socioculturales que mantenían. 


\section{LOS RESULTADOS DEL ESTUDIO ARQUEOMÉTRICO}

El estudio arqueométrico fue desarrollado en el Centro de Investigación y de Restauración de los Museos Franceses (C2RMF, Museo del Louvre, París). Fue completado por medidas de color sobre la huaca de la Luna realizadas con un sistema de colorimetría portátil por el equipo de conservación del sitio, y por análisis hematológicos efectuadas por el Instituto Genético Nantes Atlántico (IGNA).

\section{1. El protocolo experimental}

\section{1. 1. Los métodos de observación}

La colorimetría. La mayoría de nuestras investigaciones se basa en el estudio de las mezclas colorantes y de los pigmentos. El criterio de «color» es, por ende, fundamental. Sin embargo, la apreciación de un color puede cambiar de un observador a otro. Es, entonces, indispensable cuantificarlo de manera objetiva, utilizando un lenguaje científico y referencias inteligibles para toda la comunidad científica: la colorimetría. Esta técnica de medida del color es particularmente empleada en restauración/conservación porque permite seguir en el tiempo la evolución de un color y, en algunos casos, caracterizar los pigmentos. Toma en cuenta tres factores distintos: la luz incidente, la superficie del objeto iluminado y el órgano receptor que puede corresponder al ojo humano o a un aparato de medida. Hablamos en consecuencia de colorimetría «visual» o «instrumental». La colorimetría visual se basa en la observación humana del color y su comparación con muestrarios de referencias para identificarlo. En este caso, hemos utilizado el Atlas Munsell. Este método permite codificar un color según su color, su claridad y su saturación, pero depende de cada persona y su precisión no es óptima. Por eso teníamos que complementar estas primeras observaciones con un sistema independiente del factor humano: la colorimetría instrumental. Esta técnica se basa en dos etapas distintas: la primera, de medidas físicas y, la segunda, de tratamiento de los datos para definir los colores. En el marco de este estudio, fueron utilizados dos aparatos de medida: el espectro colorímetro en laboratorio y un colorímetro sobre el terreno. Las medidas efectuadas fueron después traducidas en dos diagramas matemáticos distintos: el sistema Yxy y el espacio cromático $L^{*} a^{*} b^{*}$. Esta técnica, no destructiva, nos permite disponer de las coordenadas matemáticas de cada color de manera objetiva. Esta cuantificación precisa autoriza varias comparaciones entre cada muestra o mural.

La lupa binocular (LB) nos permite describir la fisonomía general de las muestras según una ampliación de 7,5 hasta 50 veces. Nos ofrece una serie de informaciones de base completadas por los otros métodos.

La microscopía óptica (MO) permite realizar observaciones con diferentes ampliaciones (x50, x100, x200 o x500) sobre cortes transversales. En efecto, las muestras son incluidas en resina poliéster, cortadas y pulidas, para observar su 
sección y más bien su estratigrafía. Sobre las muestras de murales, nos permite obtener informaciones sobre el número de capas pictóricas superpuestas y estudiar las cualidades de los materiales sobre cada capa de pigmento o capa de soporte.

\section{1. 2. Los análisis elementales}

La microscopía electrónica de barrido acoplada a un sistema de análisis en dispersión de energía (MEB-EDS) fue aplicada sobre los cortes estratigráficos tras haber realizado las observaciones en LB y MO. El MEB es una técnica de imaginería que permite ampliaciones hasta $\times 300.000$. Para mejorar la cualidad de las imágenes, los materiales no conductores fueron cubiertos con una fina capa de carbón o de oro, dependiendo del tipo de muestras por observar. Para nuestro estudio, hemos utilizado dos tipos de imágenes: en electrones secundarios, para obtener informaciones sobre la superficie y la topografía de la muestra; y en electrones retrodifundidos obteniendo imágenes con contrastes que dependen del número atómico de los elementos químicos componiendo el material. El sistema de análisis acoplado al MEB, nos indica la composición de la muestra. Es elemental porque permite identificar los elementos químicos (átomos) componiendo el material sin identificar las moléculas de las cuales forman parte. Este análisis se traduce bajo la forma de un espectro, representando el número de rayos $\mathrm{X}$ detectados en función de su energía. Su lectura permite identificar los elementos químicos presentes en la zona de análisis nunca superior a algunos $\mu \mathrm{m}$. Esta respuesta puede también ser explotada en forma de imágenes $X$, ilustrando la repartición espacial de cada elemento químico encontrado. En el C2RMF, hemos utilizado dos aparatos MEB-EDS: un Jeol JSM-840 para los materiales minerales, y un Philips XL 30CP a presión parcial para estudiar las muestras de fibras vegetales o animales. Hemos trabajado con una tensión de aceleración de 10 a 20 kV.

Esta etapa de la metodología es primordial. En efecto, permite complementar las primeras observaciones pero lleva también a los primeros datos de composición, en función de los cuales orientaremos el resto del protocolo con una técnica de análisis estructural complementaria adaptada.

\section{1. 3. Los análisis estructurales}

La difracción de rayos $\mathbf{X}$ (DRX) es una técnica cualitativa y a veces cuantitativa empleada para caracterizar los productos minerales. Permite identificar las fases cristalinas de una muestra, sus proporciones y su grado de cristalización. Fue aplicada sobre muestras molidas en polvo o directamente sobre la superficie del fragmento de mural. Para nuestro estudio, hemos utilizado un difractómetro D5000 Brüker, en configuración $\theta-2 \theta$. Nos permitió trabajar sobre las muestras minerales arqueológicas y geológicas. Este método ha sido muy útil para identificar las clases de arcillas y pigmentos encontrados.

La espectrometría infrarroja por transformada de Fourrier (IRTF) es una técnica de espectrometría vibracional cualitativa y a veces cuantitativa de las estructuras 
moleculares. Permite caracterizar las funciones químicas de los productos orgánicos, inorgánicos, cristalizados o amorfos.

Para nuestra investigación, hemos trabajado sobre pastillas de $\mathrm{KBr}$ con un espectrómetro infrarrojo Perkin Elmer Spectrun 2000, en el medio infrarrojo $(2,5$ a $25 \mu \mathrm{m})$ en transmisión. Este método tuvo un rol preponderante, pues es aplicable a los materiales minerales pero también orgánicos como los aglutinantes.

La micro espectrometría Raman $(\mu \mathbf{R})$ es una técnica de análisis estructural óptica de espectrometría vibracional que utiliza la simetría de las moléculas. Permite caracterizar los materiales orgánicos e inorgánicos, amorfos y cristalinos. Además, no necesita una preparación particular de la muestra. En el laboratorio, hemos trabajado con un micro espectrómetro Raman Jobin-Yvon Infinity, equipado de dos láseres visibles (633 y $532 \mathrm{~nm}$ ). La resolución espacial es de $3 \mathrm{~nm}$ y la resolución espectral de $2 \mathrm{~nm}$. Hemos utilizado principalmente el láser verde (532 nm) con respecto a nuestro material. En nuestro protocolo, fue la última técnica de análisis estructural empleada y fue sobre todo útil para complementar los precedentes análisis. En efecto, es un método no destructivo y el diámetro de la zona de análisis es muy restringido (de 2 a $10 \mu$ m según el objetivo) permitiéndonos trabajar sobre superficies muy pequeñas o lagunosas. Además, es muy eficaz para diferenciar los componentes de tipo carbón, al contrario de las demas técnicas.

El protocolo desarrollado requiere varias técnicas: elemental (MEB-EDS) y estructurales (DRX, IRTF y $\mu$ R). Cada una entrega una serie de resultados, pero es la combinación de todas y el cruzamiento de los datos que nos permite caracterizar de manera precisa y segura la composición de una muestra. Además, permite trabajar sobre los productos minerales pero también orgánicos: los materiales pictóricos, los soportes, y luego sobre las fibras (animales o vegetales) y los aglutinantes.

\section{1. 4. Los análisis orgánicos}

Las pruebas microquímicas permiten poner en evidencia la presencia de materias orgánicas tales como las proteínas y el almidón, y son muy útiles para trabajar sobre los aglutinantes. Consisten en poner una gota de reactivo sobre la superficie de la muestra para observar una coloración característica. Para identificar y diferenciar las proteínas, se utilizan tres reactivos del mismo colorante: el Negro Amida (Naftol Azul Negro), pero con pH distintos. Una reacción positiva se traduce por una coloración azul cuya intensidad varía en función de la concentración de proteínas. Los tres reactivos permiten diferenciar tres componentes: yema de huevo, proteínas en general y colas de tipo gelatina. La prueba para el almidón se realiza con un reactivo llamado Lugol (solución acuosa de Yodo $\left(\mathrm{I}_{2}\right)$ y de Potasio Yoduro $(\mathrm{KI})$ ). Una reacción positiva se traduce por una coloración morada a marrón de las partículas de almidón.

Los análisis hematológicos permiten detectar las huellas de sangre con dos pruebas distintas: la prueba de Meyer y la prueba Hexagon OBTI; y luego buscar la presencia de ADN. El reactivo de Meyer permite poner en evidencia, gracias 
a un indicador colorado, la peroxidaza, una enzima contenida en la sangre. Se aplica a la sangre animal y humana. La prueba Hexagon OBTI permite la detección inmunológica específica de la hemoglobina humana hasta una concentración de $0,1 \mu \mathrm{g} / \mathrm{L}$, es decir presente en muy pequeña cantidad. Por fin, estas pruebas fueron completadas con una búsqueda de ADN.

\section{1. 5. Conclusiones}

Este protocolo analítico nos permitió estudiar la totalidad del material seleccionado, que sea de origen mineral u orgánico. Pudimos trabajar sobre los fragmentos de murales, las muestras de pigmentos naturales, las fibras animales y vegetales, las muestras de vegetales, y sobre la caracterización de huellas de sangre.

\section{2. Los resultados sobre la huaca de la Luna, Complejo de Moche, Valle de Moche}

Los análisis sobre los murales de la Huaca de la Luna, nos permitieron obtener informaciones inéditas sobre los materiales empleados y más generalmente sobre la tecnología artística desarrollada por los artesanos pintores del sitio.

\section{2. 1. La preparación del soporte}

La composición silto-arcillosa del soporte nos lleva a clasificarlo geológicamente en el grupo de los «mudrocks» o «rocas de barros», grupo que reúne todos los sedimentos siliciclásticos, constituidos principalmente de elementos del tamaño de los siltes (limos) $(4$ a $62 \mu \mathrm{m})$ y de las arcillas $(<4 \mu \mathrm{m})$ (Boulvain, 2004). En efecto, está esencialmente compuesto de cuarzo, de aluminosilicatos calcosódicos y potásicos, y de arcilla rica en hierro que le confiere su color amarilloanaranjado. Los análisis indicaron también la presencia de monazitas, inclusiones minerales consecuencias de la degradación de las rocas graníticas que constituyen un marcador geológico. La cantidad importante de materia, necesaria para la confección de los soportes, y la presencia de estos marcadores convergen para demostrar su origen local.

Por otro lado, su composición, su granulometría y su porosidad, confieren a este material compuesto y detrítico una excelente inercia térmica e higrométrica, traduciéndose por una regulación de las diferencias de temperatura y de humedad del soporte que, por esta razón, es menos frágil. La diferencia de granulometría entre el muro y la capa pictórica (de granulometría más fina) favorece la adherencia de la capa de pigmentos que penetra en el soporte más profundamente. Las observaciones en sección indicaron también una preparación del muro antes de la aplicación de la mezcla colorante. En efecto, fue alisado en superficie, acción que permitía al artista trabajar sobre un soporte plano. Este alisado se traduce por una acumulación de microcristales que suben por capilaridad encima de la capa soporte. Sin embargo, hemos notado la ausencia de una capa preparatoria blanca, 
propuesta por varios autores (Bonavia, 1985; Franco et al., 1994; Campana \& Morales, 1997).

\section{2. 2. La preparación de la mezcla colorante}

La receta. Hasta ahora las investigaciones sobre el arte mural precolombino habían concernido únicamente la caracterización del elemento colorante: el pigmento. Ahora bien, nuestras experimentaciones permitieron entender que la mezcla colorante se compone de varios «ingredientes»: pigmentos, cargas y aglutinantes (fig. 1).

Los pigmentos blanco, rojo y amarillo son todos de origen mineral, mientras el negro es orgánico. Los pigmentos blancos corresponden a dos arcillas, la caolinita $\left(\mathrm{Al}_{2} \mathrm{Si}_{2} \mathrm{O}_{5}(\mathrm{OH})_{4}\right)$ y la ilita $\left(\left(\mathrm{K}, \mathrm{H}_{3} \mathrm{O}\right)(\mathrm{Al}, \mathrm{Mg}, \mathrm{Fe})_{2}(\mathrm{Si}, \mathrm{Al})_{4} \mathrm{O}_{10}\left[(\mathrm{OH})_{2},\left(\mathrm{H}_{2} \mathrm{O}\right)\right]\right)$, a las cuales se añadía hematita $\left(\mathrm{Fe}_{2} \mathrm{O}_{3}\right)$ para hacer el rojo y goetita $(\mathrm{FeO}(\mathrm{OH}))$ para el amarillo, en proporciones variables en función del color deseado. El negro es constituido de carbón de madera mientras que la mezcla identificada como «azul» corresponde de hecho a un gris resultado de la asociación de las mezclas blanca y negra.

Los datos obtenidos sobre los coadyuvantes, así como sobre las cargas y los aglutinantes, son inéditos. Dos tipos de cargas fueron empleados: yeso $\left(\mathrm{CaSO}_{4}, 2 \mathrm{H}_{2} \mathrm{O}\right)$ para las mezclas blanca, roja y amarilla, y calcita $\left(\mathrm{CaCO}_{3}\right)$ para el negro. Estos dos minerales son preparados en forma de polvos, ambos blancos, y son añadidos a los pigmentos para mejorar la cohesión de la mezcla y su recubrimiento sobre el soporte. En casos excepcionales, el yeso fue también empleado como capa preparatoria o depositado en la superficie de la capa pictórica para conferirle una cierta brillantez.

Dos aglutinantes distintos fueron añadidos para ligar la mezcla y mejorar su adhesión sobre el soporte: una cola proteínica de origen animal, y savia del cactus San Pedro (Trichocereus pachanoi). Estos resultados, aunque preliminares, son importantes, pues constituyen los primeros datos analíticos sobre los aglutinantes orgánicos empleados en el arte mural moche.

El origen de los pigmentos. Los análisis elementales realizados sobre las capas pictóricas indicaron la presencia de marcadores geológicos de tipo monazitas e inclusiones metálicas cobre/estaño. Estas monazitas fueron también detectadas sobre las capas soportes y sobre las muestras de pigmentos naturales de la cantera de Conache (1,5 km al norteste de la huaca de la Luna, sobre la margen derecha, del Río Moche), tendiendo a demostrar el origen local de estos materiales.

Además, el estudio de los pigmentos de Conache mostró que varios pigmentos utilizados en los murales de la huaca de la Luna se encontraron cerca del sitio. En efecto, hemos caracterizado la presencia de hematita, de goetita, de ilita, de yeso y de calcita. Aunque las venas de pigmentos analizadas no son forzosamente las explotadas por los artistas mochicas, su composición indica su disponibilidad local, confirmando la hipótesis de la procedencia local de la mayoría de los materiales pictóricos empleados. 


\section{2. 3. Las herramientas}

Los vestigios de herramientas utilizadas por los artesanos pintores moches son excepcionales. Sin embargo, gracias al estudio arqueométrico pudimos observar y analizar fibras animales entrampadas en las capas pictóricas (fig. 3), que luego hemos comparado con fibras de referencia. Así pudimos mostrar el empleo de herramientas de tipo pinceles elaborados con pelos de camélidos, muy probablemente de llama, para aplicar el color sobre el soporte (fig. 4). Aunque el tamaño y la fisonomía de estos pinceles queden a determinar, estos primeros resultados son muy importantes porque inéditos.
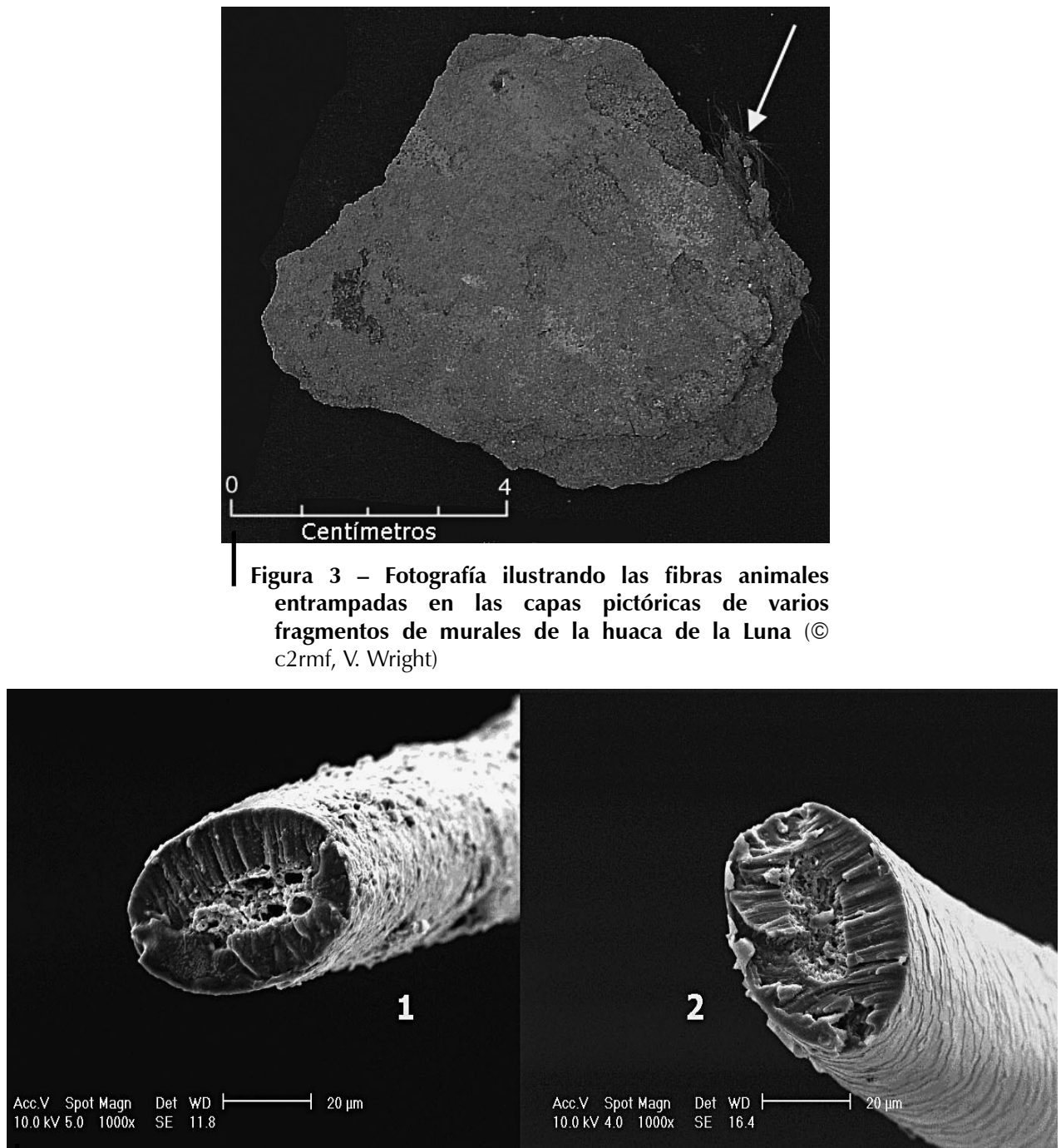

Figure 4 - Imágenes MEB en electrones retrodifundidos de una fibra arqueológica (1) y de una fibra referencia de Ilama (2) a una ampliación x 1000, indicando una correspondencia (C) c2rmf, V. Wright) 


\section{2. 4. La dimensión mágico religiosa del mural}

Los murales tenían una función decorativa pero también un rol y una significación mucho más simbólicos. Con una iconografía dedicada a las actividades rituales y en particular a la ceremonia de sacrificio, su dimensión mítica es evidente. Ahora bien, algunos ingredientes añadidos intencionalmente a las mezclas colorantes, permitieron confirmar y materializar este carácter místico y sobrenatural.

Sobre todas las capas pictóricas, los análisis elementales permitieron detectar inclusiones de fosfatos de calcio. Es muy probable que correspondan a hidroxilapatita, una forma de apatita de calcio de formula química $\mathrm{Ca}_{5}\left(\mathrm{PO}_{4}\right)_{3}(\mathrm{OH})$. Estos elementos se encuentran bajo forma mineral en la naturaleza, pero son igualmente producidos por los huesos. Ahora bien, el hueso puede tener un rol particular en el seno de la mezcla colorante. En efecto, el polvo de hueso es una carga a menudo empleada en pintura. Podemos pues proponer que los cristales de hidroxilapatita encontrados sobre las capas pictóricas de la huaca de la Luna corresponden a polvo de hueso añadido intencionalmente a la mezcla. Por otro lado, algunos análisis de caracterización sobre cerámicas finas mochicas mostraron el añadido de hueso molido al pigmento rojo (Swann et al., 1999) tendiendo a confirmar nuestra hipótesis. Además, sobre algunos murales como en huaca Cao Viejo, fragmentos de huesos humanos o animales fueron insertados en la pared, dándole una dimensión simbólica y casi humanizando los personajes representados. El hueso tendría así una función técnica de carga pero también un rol mucho más simbólico. Añadiendo elementos palpables de seres humanos en las mezclas colorantes, el artista rinde la escena real, legitimando y apoyando su significación.

Las experimentaciones mostraron también el uso de savia de cactus como aglutinante, muy probablemente de San Pedro (Trichocereus pachanoi) cuya elección no parece anodina. En efecto, este vegetal fue conocido y utilizado por los mochicas por sus virtudes alucinógenas (Bourget, 1994; Larco Hoyle, 2001; Uceda \& Tufinio, 2003), en particular durante las ceremonias de sacrificio. Gracias a su poder psicotrópico, fue supuesto conferir a sus consumidores la posibilidad de rendirse en el mundo de los Ancestros y así sobrepasar su condición de simples mortales. Ahora bien, la iconografía de los murales está estrechamente asociada a la ceremonia de sacrificio y el añadido de esta sustancia vegetal podría así conferir a la pintura una dimensión espiritual suplementaria. En efecto, la savia de San Pedro podía materializar y concretizar el mensaje simbólico transmitido por el mural, dándole una realidad y una existencia física. El mural mismo se vuelve un «puente» entre el mundo de los «Vivos» y de los «Ancestros».

Añadir polvo de hueso y savia de San Pedro a las preparaciones pictóricas tiene, por lo tanto, un rol técnico, pero también una función mucho más simbólica. Las escenas pintadas no son solamente decorativas pero se vuelven «vivas». Gracias al mensaje que transmiten y a estos ingredientes míticos, su rol sagrado es evidente.

\section{2. 5. El mural y su rol participativo a los rituales}

Las investigaciones recientes del PAHL indican que los espacios con los murales identificados como Temas Complejos, al pie del Frontis Norte, fueron en estrecha 
relación con las actividades de la ceremonia de sacrificio y más precisamente con la presentación de la sangre (Tufinio, 2006). Ahora bien, el estudio de los Muros Complejos permitió observar rastros marrones indeterminados sobre varias zonas. La localización de estas huellas y la iconografía de los murales asociados llevaron a los arqueólogos y conservadores del sitio a proponer que se trataba de rastros de sangre. Hemos entonces sacado nueve muestras sobre estos depósitos para estudiarlas analíticamente.

Las investigaciones al C2RMF permitieron explicar que estos depósitos marrones son constituidos de elementos discoidales de 5 a $6 \mu$ m de diámetro, cóncavos en su centro (fig. 5). Estos elementos se parecen a hematíes «fósiles» (Hortolà, 2002) que contienen la hemoglobina, dando el color a la sangre, la cual expuesta al aire, se oxida y se hace marrón, lo que explicaría el color de este depósito. Normalmente, los glóbulos rojos presentan un tamaño medio de $7 \mu \mathrm{m}$, pero sabemos que varios factores pueden provocar una disminución del tamaño: la edad de las hematíes, una malnutrición o carencias del sujeto, infecciones o lesiones de repetición, lo que no es incompatible con nuestro contexto de investigación.

A continuación, once muestras fueron estudiadas por el IGNA. Los análisis siguieron dos etapas: la primera consistía en poner en evidencia la presencia de sangre y la segunda en una investigación ADN. Estas experimentaciones hematológicas tienden a confirmar la presencia de sangre que no sería de origen humano, pero estos resultados son preliminares. Además, el carácter degradado del ADN (posiblemente debido a condiciones medioambientales de conservación desfavorables, como la exposición a la luz, al calor o a la humedad) no nos permitió desarrollar estos primeros resultados.

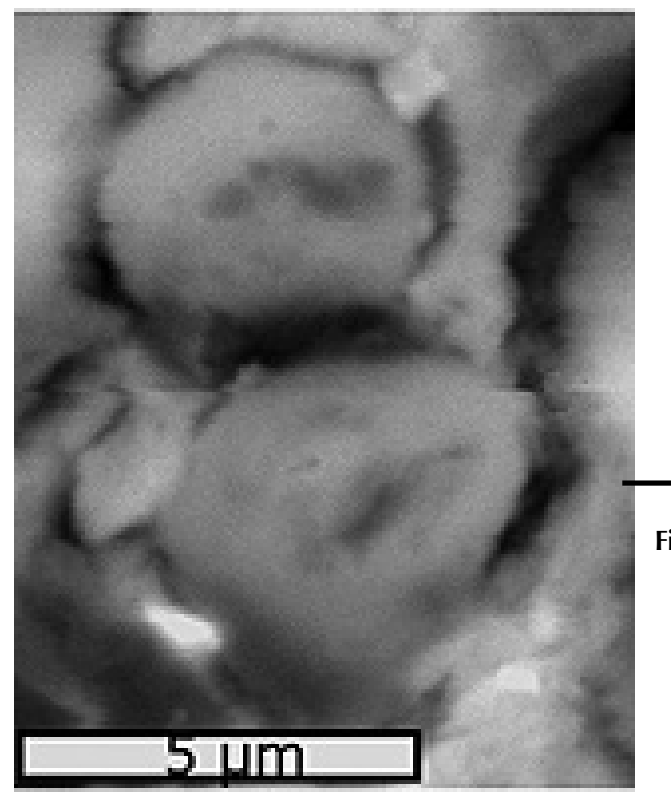

Figura 5 - Imagen MEB en electrones retrodifundidos a una ampliación x $\mathbf{8 0 0 0}$ de la capa marrón de la muestra sacada sobre el muro interno sur del recinto $1 \mathrm{del}$ Edificio A.

Permite notar la presencia de hematíes fósiles de 5 a $6 \mu \mathrm{m}$ de diámetro (C) c2rmf, V. Wright). 
Por fin, la localización de estas huellas sobre zonas precisas del mural, y su penetración en el muro (más de 1,5 mm según las observaciones en sección) indican que fueron asperjados de manera repetitiva. Estas proyecciones de sangre no corresponden a una acción fortuita sino a un «rito» preciso.

Más allá de las problemáticas de tecnología pictórica, los análisis físico químicos permitieron entender y demostrar la importancia y el grado sagrado que revestía el arte mural en la sociedad mochica.

\section{3. Los resultados sobre todo el territorio}

\section{3. 1. La huaca Cao Viejo, Complejo El Brujo, Valle de Chicama}

Los soportes. El estudio de los soportes mostró que correspondían a un sedimento calcáreo más o menos rico en arcilla. Sobre el Edificio E, hemos puesto en evidencia la presencia de caolinita e ilita, arcillas ausentes sobre los soportes del edificio D. Esta diferencia se observa igualmente al nivel de la fisonomía: las muestras del Edificio E presentan una granulometría más grosera y heterogénea y un color más anaranjado.

Las mezclas colorantes. Los análisis permitieron entender que la mezcla colorante se compone de tres elementos de base: pigmentos, cargas y aglutinantes. Los pigmentos blanco, rojo y amarillo son minerales aunque el negro es orgánico. El blanco corresponde a una mezcla de calcita y arcilla, el rojo a hematita, el amarillo a goetita, el negro a un carbón de madera, y el gris a una mezcla de blanco (calcita + arcilla) y de negro (carbón de madera). Las mezclas colorantes blancas y negras son idénticas sobre las dos fases constructivas estudiadas. Sin embargo, a los pigmentos rojos y amarillos se añaden otros elementos cromógenos que divergen entre los dos edificios. Sobre el Edificio E, el artesano ha añadido calcita y una arcilla rica en hierro, aunque sobre el edificio D la hematita es completada de calcita, de arcilla rica en hierro y de caolinita, y la goetita únicamente de una arcilla rica en hierro. Esta observación tiende pues a confirmar las diferencias ya observadas sobre los soportes entre los Edificios D y E.

Dos tipos de cargas fueron añadidos a los pigmentos: calcita y yeso, preparados en forma de polvos. Como para la huaca de la Luna, el yeso asociado a la calcita fue reservado a los blancos, rojos, amarillos y gris, aunque la calcita sola fue mezclada con el pigmento negro. Por otra parte, dos elementos orgánicos fueron utilizado como aglutinantes: un producto proteínico cuya composición exacta queda indeterminada, y savia de San Pedro (fig. 1). Sin embargo esta sustancia vegetal no fue caracterizada sobre las mezclas colorantes blancas.

El origen de los materiales. El estudio de las mezclas colorantes nos reveló la presencia recurrente de calcita. Ahora bien, el valle de Chicama posee yacimientos importantes de carbonatos de calcio lo que sugería un origen local de los materiales empleados. Además, como para la huaca de la Luna, hemos puesto en evidencia monazitas pero asociadas a inclusiones metálicas particulares de tipo cromo/ hierro/níquel, indicando un origen geológico diferente probablemente local. 


\section{3. 2. Castillo de Huancaco, Valle de Virú}

Los soportes. Los datos de composición obtenidos sobre los soportes nos permiten precisar que corresponden a un sedimento silto arcilloso clasificado en el grupo de los «mudrocks» («rocas de barro»), compuesto esencialmente de cuarzo, feldespatos (aluminosilicatos calco sódicos y potásicos) y minerales arcillosos (Boulvain, 2004). Su color amarillo-anaranjado es debido a la presencia de óxidos de hierro. Por otro lado, los análisis mostraron inclusiones de tierras raras, monazitas, y partículas ricas en metal (cromo/hierro/níquel, mercurio y tungsteno) e inclusiones metálicas (cobre/estaño). Estas monazitas se encuentran también en los otros sitios pero asociadas con otras inclusiones metálicas. Entonces podemos proponer que los materiales de Castillo de Huancaco tienen un origen geológico diferente de los otros complejos.

Las mezclas colorantes. Los análisis permitieron entender que el blanco es obtenido mezclando calcita y una arcilla, y el gris mezclando este blanco con carbón de madera. Dos mezclas rojas fueron identificadas: la primera compuesta de hematita y arcilla rica en hierro, y la segunda hematita, arcilla ferrosa y cinabrio que parece aplicado en superficie de la capa pictórica. Pudimos también caracterizar dos mezclas amarillas: la primera compuesta de goetita y una arcilla ferrosa, la segunda con estos elementos más cinabrio, dando un color más anaranjado. Por fin, encontramos un pigmento verde obtenido por asociación de dos minerales cuprosos: la atacamita $\left(\mathrm{Cu}_{2} \mathrm{Cl}(\mathrm{OH})_{3}\right.$ y la malaquita $\left(\mathrm{Cu}_{2}\left(\mathrm{CO}_{3}\right)\right.$ $(\mathrm{OH})_{2}$ ). Entonces, varias singularidades fueron identificadas en este sitio: la gama cromática clásica empleada por los mochicas es completada por el color verde. La utilización de este color permanece excepcional, y fue atestada únicamente en contexto arqueológico en La Mina, en el valle de Jequetepeque, en la región Mochica Norte. Por otro lado, el uso de cinabrio asociado a las mezclas colorantes rojas y amarillas es muy raro y se notó hasta ahora únicamente en el sitio de la Mayanga en el valle de La Leche, en la región Mochica Norte (fig. 1).

Sobre las capas pictóricas, no hemos observado un tipo particular de marcador geológico (monazitas o inclusiones metálicas). Sin embargo, el empleo de cinabrio y del pigmento verde permite constatar una particularidad local en la elección de las materias primas. Por fin, pudimos mostrar que la mezcla colorante fue completada por una carga (yeso e/o calcita) y un aglutinante (cola proteínica), siguiendo una receta de elaboración idéntica a los otros sitios estudiados.

\section{3. 3. La Plataforma Funeraria de Sipán, Valle de Lambayeque}

Los soportes. El estudio analítico permitió concluir que los soportes corresponden a un sedimento silto arcilloso, geológicamente asociado al grupo de los «mudrocks» puesto que es compuesto de cuarzo, feldespatos (aluminosilicatos calco sódicos y potásicos) y minerales arcillosos (Boulvain, 2004). Por otra parte, pudimos identificar una inclusión de monazitas y también muchos cristales de sulfato de bario correspondiendo a barita $\left(\mathrm{BaSO}_{4}\right)$. Ahora bien, numerosas venas de barita fueron localizadas en el valle de Lambayeque. La cantidad de material necesaria 
y esta presencia recurrente de barita permiten proponer un origen local de los materiales empleados para realizar estos soportes.

Las mezclas colorantes. Los análisis permiten concluir que el blanco es compuesto de arcilla, el rojo de hematita y arcilla ferrosa, el amarillo de goetita y arcilla rica en hierro, y el negro de carbón de madera. Además varias especificidades fueron caracterizadas: el gris resulta de la mezcla de negro, amarillo, rojo y blanco aunque en los sitios estudiados en la región Sur corresponde a la mezcla de blanco y negro. Por otro lado pudimos observar la presencia del color morado, compuesto de negro y rojo, cuyo uso en Sipán permanece un ejemplo único (fig. 1).

Pocos datos fueron adquiridos sobre el origen de los materiales colorantes. En efecto, ninguna inclusión de tierra rara o metálica fue detectada. Para complementar estos resultados hemos comparado las muestras arqueológicas con muestras de pigmentos naturales sacadas del Cerro de la Pinturas, cantera de pigmentos ubicada a $2 \mathrm{~km}$ al sureste de la plataforma funeraria. Las comparaciones no nos permitieron sacar conclusiones de origen geológico, pero pudimos atestar de la disponibilidad local de algunos pigmentos empleados en Sipán (hematita y goetita). Por fin, hemos determinado el uso de yeso y de calcita, muy probablemente como cargas, pero no pudimos caracterizar la presencia de aglutinante (fig. 1).

\section{4. Conclusiones}

Las investigaciones analíticas fueron aplicadas a tres centros administrativos mayores de la región sur y uno del territorio norte. Nos permitieron adquirir numerosos datos inéditos sobre los murales, relieves o pinturas: la elección de los materiales y su origen geológico, las herramientas y las técnicas pictóricas empleadas, y así entender la tecnología artística desarrollada y seguida por los artesanos pintores mochicas.

Los análisis precedentes se concentraron esencialmente sobre la caracterización del elemento cromógeno. Al contrario, nuestras investigaciones concernieron todos los materiales utilizados para realizar un mural. Así hemos adquirido informaciones sobre la naturaleza de las capas soportes, sus composiciones y sus modos de preparación. Sobre los sitios de Moche, Castillo de Huancaco y Sipán, corresponden a un sedimento silto-arcilloso y a El Brujo a un sedimento calcáreo rico en arcillas. Por otro lado pudimos cada vez poner en evidencia marcadores geológicos (monazitas e inclusiones metálicas). La gran cantidad de material necesaria para elaborar estos soportes y estos indicios de procedencia convergen para mostrar un origen local, regional de estos materiales.

Además, pudimos mostrar que la granulometría de las capas soportes es mucho más grosera y heterogénea que las capas pictóricas, favoreciendo así la adherencia de la mezcla colorante sobre el muro. Por fin sobre los murales de la huaca de la Luna pudimos observar las huellas de una acción de alisado de superficie del muro, traduciéndose por una granulometría más fina del soporte al contacto de la capa pictórica. Fue también interesante observar que, sobre todos los sitios y al 
contrario de lo que argumentaban varios estudios precedentes, la capa pictórica es aplicada directamente sobre su soporte en tierra cruda sin capa preparatoria blanca (Bonavia, 1985; Franco et al., 1994 ; Morales, Solórzano \& Asmat, 1998).

En cuanto a las mezclas colorantes, pudimos entender que no correspondían solamente al uso de un pigmento pero que resultaban de una verdadera receta. Esta receta está compuesta de tres ingredientes de base: elementos colorantes, cargas y aglutinantes, cada uno poseyendo propiedades físicas específicas. Esta receta fue aplicada sobre los cuatro complejos arqueológicos estudiados.

Los elementos colorantes corresponden a pigmentos de origen mineral y orgánico, empleados solos o mezclados para matizar un tono o crear un nuevo color. Varios son utilizados de manera recurrente como la calcita para el blanco, la hematita para el rojo, la goetita para el amarillo y el carbón de madera para el negro (fig. 1). A pesar de estas similitudes, pudimos observar varias particularidades, principalmente en la composición de algunos pigmentos y en la gama cromática empleada por los artesanos pintores trabajando sobre cada uno de los sitios estudiados. En efecto, pudimos notar el uso del morado en Sipán, del cinabrio para el rojo y del color verde en Castillo de Huancaco, por ejemplo, ilustrando estas singularidades locales.

Además, gracias a todos los datos adquiridos sobre los pigmentos arqueológicos o sacados en las canteras naturales, pudimos proponer un origen generalmente local de los materiales empleados. Esta conclusión permitiría pues explicar las distinciones en la elección de las materias primas observadas sobre cada edificio ritual.

Dos tipos de cargas fueron caracterizados sobre todos los sitios: el yeso y la calcita. Además, es interesante constatar que el yeso es generalmente reservado a los colores blancos, rojos y amarillos, aunque la calcita sola es utilizada para el negro. Añadir una carga precisa a un pigmento parece pues una elección intencionada, muy posiblemente debido a las propiedades físico químicas de cada elemento en presencia.

Por otra parte, dos aglutinantes, ambos orgánicos, fueron detectados. El primero corresponde a una substancia rica en proteínas, parecida a una cola de tipo gelatina, cuya composición exacta permanece indeterminada. El segundo es elaborado con savia de San Pedro, cactus representado de manera abundante en la costa norte de Perú. Este San Pedro se encontró añadido a las mezclas colorantes sobre los sitios de Moche y El Brujo. Análisis complementarios sobre los otros complejos (Castillo de Huancaco y Sipán) permitiría quizás atestar su utilización.

Por fin, varios ingredientes con propiedades técnicas pero también simbólicas fueron identificados. La presencia de San Pedro, cuyas propiedades alucinógenas son conocidas y explotadas por los mochicas, y el posible añadido de polvo de hueso, que hemos encontrado sobre cada sitio estudiado, confieren al mural una dimensión espiritual que fortalece el mensaje ideológico transmitido a través de la iconografía y el carácter sagrado de los adornos y de los espacios arquitectónicos a los cuales están asociados. La imagen se vuelve entonces un medio de comunicación no solamente con el pueblo pero también entre el mundo de los Vivos y él de los Ancestros. 


\section{CONCLUSIONES E INTERPRETACIONES}

Las investigaciones analíticas sobre el arte mural de los sitios de Moche, El Brujo y Castillo de Huancaco, en la región sur, y de Sipán en la región norte, nos permitieron adquirir datos inéditos en cuanto a la técnicas pictóricas, pero sobre todo entender la evolución espacio temporal de la tecnología artística empleada sobre todo el territorio, así como la organización de este actividad artesanal singular.

\section{1. Tecnología pictórica y territorio mochica}

\section{1. 1. La evolución temporal de las técnicas}

Gracias a un muestrario representativo pudimos trabajar sobre murales de cada fase constructiva de la huaca de la Luna. Luego hemos completado las investigaciones ya empezadas sobre la huaca Cao Viejo. Así hemos adquirido datos analíticos cubriendo varios siglos de ocupación, lo que nos permite, comparando los resultados, seguir la evolución de las técnicas artísticas en el tiempo sobre estos dos complejos administrativos mayores.

En cuanto a la huaca de la Luna, trabajar sobre muestras de murales de los Edificios E, D, B/C y A y de la Plataforma III, permitió hacer comparaciones y seguir la evolución de las técnicas pictóricas del $3^{\text {er }}$ siglo al $8^{\text {vo }} 9^{\text {no }}$ siglo d. C. Pudimos constatar que las capas soportes presentaban las mismas características (fisonomía, composición y técnica de alisado) del Edificio E a la Plataforma III. Estas observaciones son válidas para las mezclas colorantes. En efecto, no solamente la «receta» sino también los «ingredientes» son idénticos en todos los edificios considerados. Hemos detectado los mismos marcadores de procedencia (monazitas e inclusiones metálicas) sobre todo el material, lo que nos permite proponer un origen local común a estos materiales, y por lo tanto, la explotación de las mismas fuentes, o de fuentes muy cercanas durante varios siglos. Por fin, fibras de pinceles en pelos de camélidos fueron localizadas sobre muestras sacadas sobre los Edificios D y A, demostrando el empleo de herramientas muy similares a lo menos durante este periodo.

Todas estas observaciones permiten poner en evidencia una continuidad temporal en el uso de las materias primas y de las técnicas artísticas. Los artesanos han utilizado los mismos materiales, originarios de fuentes minerales idénticas o muy similares, los mismos métodos de preparación de los soportes y de las mezclas colorantes, y finalmente las mismas herramientas. La tecnología pictórica seguida para elaborar un mural en la huaca de la Luna permanece idéntica durante cinco fases constructivas. Esto sugiere que existía una transmisión del conocimiento técnico y de una generación a otra de artesanos pintores.

En la huaca Cao Viejo, las investigaciones sobre los Edificios E y D, ocupados del principio de nuestra era al $3^{\text {er }}-4^{\text {to }}$ siglo d. C., nos permitieron también sacar varias conclusiones sobre la evolución de las técnicas pictóricas. En efecto, pudimos notar 
una receta de elaboración de las mezclas colorantes idéntica en cada edificio, así como los pigmentos, las cargas y los aglutinantes que se quedan idénticos durante tres siglos de ocupación. Estos resultados indican una continuidad temporal de las técnicas pictóricas en el sitio, y tienden a mostrar que existía en la huaca Cao Viejo, como en la huaca de la Luna, una transmisión del conocimiento técnico de una generación a otra de artesanos pintores. Esta observación conforta las conclusiones de los análisis preliminares realizadas por Kakoulli, que indicaba una continuidad en el tiempo en la elección de las materias primas (Kakoulli, 1997).

\section{1. 2. La evolución espacial de las técnicas}

Cruzar los datos analíticos adquiridos sobre los murales de Moche, El Brujo, Castillo de Huancaco y Sipán, permitió observar similitudes en las técnicas pictóricas aplicadas sobre cada centro administrativo. En efecto, hemos siempre constatado la misma receta de elaboración de la mezcla colorante, con un elemento colorante, una carga y un aglutinante. Además, los elementos cromógenos siempre son pigmentos, de origen mineral excepto el negro identificado como carbón de madera $y$, por ende, orgánico. Varios pigmentos son utilizados de manera recurrente como la hematita para el rojo, la goetita para el amarillo; la elaboración del color gris corresponde a la misma combinación de carbón de madera y de un pigmento blanco (arcilla y/o calcita según los sitios). Dos tipos de cargas fueron caracterizados sobre cada sitio, solas o combinadas: yeso y calcita; a continuación hemos identificado dos aglutinantes recurrentes: una cola proteínica y savia de San Pedro (Trichocereus pachanoi) (fig. 1).

Estas observaciones son completadas por los datos analíticos anteriormente adquiridos sobre los sitios de La Mayanga, La Mina y Pañamarca. En efecto, podemos constatar el empleo de pigmentos análogos (cinabrio y hematita para el rojo, calcita para el blanco, y carbón de madera para el negro por ejemplo), así como el empleo de la misma técnica de obtención del gris en La Mina y Pañamarca, donde un pigmento negro es mezclado con un blanco. Por otro lado, la presencia recurrente de calcita, en La Mina y Pañamarca, nos permite suponer su utilización como carga, argumentando nuestras conclusiones (fig. 1).

Aunque algunos datos sobre la composición de los coadyuvantes (cargas y aglutinantes) son imprecisos en La Mayanga, La Mina y Pañamarca, es posible notar numerosas similitudes entre cada complejo arqueológico (fig. 1). Estas comparaciones tienden a mostrar que existía una continuidad espacial de las técnicas artísticas empleadas en la elaboración de los murales mochicas, un conocimiento técnico que se difundió y se transmitió no solamente en una misma región pero también en todo el territorio. Sin embargo, las singularidades regionales observadas, en lo que concierne por ejemplo la elección de los colores empleados (verde en Castillo de Huancaco y morado en Sipán) dejan aparecer un «margen» de improvisación local. 


\section{1. 3. El arte mural y la organización política mochica}

Las recientes investigaciones sobre la organización del territorio mochica permitieron mostrar que el poder mochica era un poder regionalizado y materializado por los grandes centros ceremoniales implantados en cada valle fluvial. La interconexión de las élites locales ha federado el pueblo gracias a una gestión política comuna. Esta permitió el mantenimiento de un poder político fuerte, y compartir una misma ideología, conocimientos y tecnologías, aunque sean conservadas identidades regionales marcadas (Castillo \& Uceda, ms.).

Ahora bien, es muy interesante constatar que este modelo de organización social se aplica precisamente a las conclusiones propuestas sobre la tecnología artística. En efecto, hemos mostrado que existían conocimientos especializados comunes a todos los centros artesanales, pero hemos notado individualidades locales. Además, las investigaciones sobre el origen de los materiales empleados tienden a mostrar un origen regional de las materias primas, explicando las diferencias de composición entre cada sitio. Parece, en efecto, que los artesanos pintores han utilizado fuentes minerales cerca de su lugar de trabajo.

Aunque esta hipótesis permite entender el uso de pigmentos diferentes sobre el territorio, es interesante notar que varios minerales son explotados de manera excepcional. En efecto, el color verde es documentado en contexto arqueológico únicamente en La Mina y Castillo de Huancaco, y el cinabrio es utilizado solamente en La Mayanga y Castillo de Huancaco, sitio que presenta entonces varias singularidades. Ahora bien, este complejo monumental ilustra, con su producción cerámica o su arquitectura, algunas diferencias locales observadas en la región sur, reflejo del proceso expansionista de los mochicas (Bourget, 2003). Parece pues que las conclusiones sacadas sobre las técnicas pictóricas correlacionan otra vez las recientes hipótesis de organización social y territorial propuestas.

Entonces, el estudio analítico del arte mural permite no solamente obtener informaciones sobre las técnicas pictóricas, sino también elementos de comprensión de la organización política y social de la cultura mochica. El arte tiene mucha importancia en esta sociedad y es también su «reflejo». Gracias a estos resultados y a estas primeras interpretaciones, es en adelante importante preguntarse sobre el rol del artesano pintor en esta sociedad. ¿Es un artesano especializado? ¿Pertenece a una clase artesanal?, y por si acaso ¿cómo se organiza? ¿Cuál es su estatus social? ¿Qué relaciones tiene con la clase gobernante? ¿Dónde trabaja? Aquí son expuestas algunas interrogantes a las cuales la investigación analítica que hemos desarrollado permitió aportar elementos de respuestas.

\section{2. ¿El arte mural: una artesanía especializada?}

\section{2. 1. Algunas nociones de «artesanía especializada»}

En las sociedades complejas, los artesanos especializados tienen un rol preponderante en su desarrollo. Transforman las materias primas, pero también una idea en una realidad tangible; crean un bien, símbolo de poder y de un 
universo ideológico. La producción especializada responde pues a necesidades económicas, sociales o políticas. Por otro lado, el control de los artesanos especializados representa una oportunidad para la clase gobernante de legitimar y consolidar su poder. Esta élite se transforma en el primer beneficiario de la producción artesanal especializada (Bernier, 2008).

Ahora bien, el arte mural corresponde a una expresión artística muy ligada a la clase gobernante. Lo utiliza como medio de comunicación privilegiado que le permite, gracias a un discurso iconográfico preciso, explicar y transmitir una ideología. El artista se vuelve pues un artesano al servicio del poder, utilizando y siguiendo códigos visuales preestablecidos, a pesar de algunas singularidades locales. Además, pudimos mostrar que los artesanos pintores son herederos de una enseñanza, de un conocimiento transmitido durante el tiempo pero también sobre todo el territorio mochica.

Elaborar un mural parece entonces representar una verdadera actividad artesanal, cuyos protagonistas siguen una formación y son dirigidos por la élite mochica quien es la principal adjudicataria beneficiaria. Los artesanos fueron probablemente instruidos sobre las diferentes técnicas pictóricas y los códigos iconográficos para volverse obreros competentes y experimentados en una tarea precisa, con una técnica constante es decir un conocimiento técnico característico de una producción especializada (Costin \& Hagstrum, 1995; Bernier, 2008) y una capacidad de adaptación a los recursos locales.

Esta noción de «artesanía especializada» permite pues proponer varios elementos sobre la organización de esta actividad, sobre la constitución de esta unidad de producción, su intensidad, su contexto y su concentración (Costin \& Hagstrum, 1995).

\section{2. 2. Organización de los artesanos pintores}

Las experimentaciones analíticas realizadas sobre vestigios de policromía mochica nos permitieron adquirir informaciones en cuanto a la cadena operativa seguida para elaborar un mural. La primera etapa identificada corresponde a la extracción de las materias primas, destinadas a la preparación de los soportes y de las capas pictóricas. Los análisis permitieron mostrar que los productos minerales empleados tienen muy probablemente un origen local, limitado al valle donde el sitio estaba implantado. El único pigmento cuya fuente estaría más alejado corresponde a la caolinita identificada en la huaca de la Luna y de manera excepcional en la huaca Cao Viejo. Los datos analíticos tienden pues a demostrar que cada centro administrativo disponía de sus propias fuentes de minerales localizadas en el valle donde estaba implantado, a excepción del caolín que hubiera sido objeto de un abastecimiento más lejano. Además, el uso de colores distintos sobre varios sitios, como el verde en Castillo de Huancaco y el morado en Sipán, ilustrando singularidades locales, constituye un elemento más para sugerir una implantación local de esta actividad artesanal. Los artesanos pintores parecen ligados a un centro político preciso que, aunque siga normas iconográficas y tecnológicas comunes a todo el territorio, funciona de manera más o menos independiente. 
Luego, es necesario preparar todos los materiales recolectados. Los pigmentos deben ser molidos de manera muy fina (del orden del micrómetro según las observaciones), y los productos orgánicos, carbón de madera y aglutinantes, necesitan también una preparación específica (combustión de la madera y molienda, confección de la cola proteínica y extracción de la savia de San Pedro por ejemplo), antes de mezclar todo. Esta etapa de la «gama» de fabricación exigía una mano de obra suficiente y una larga duración de trabajo, ya que la cantidad de materia necesaria para elaborar un mural es muy importante. En efecto, si consideramos el ejemplo del Frontis Norte del Edificio A de la huaca de la Luna, es posible realizar una aproximación. La superficie de los murales descubiertos es actualmente estimada a $2160 \mathrm{~m}^{2}$ (Morales, Asmat, Solórzano, Asmat, Sánchez, Gil, 2006, 2006). Todas las observaciones efectuadas en el marco de nuestro estudio arqueométrico permiten, por otra parte, tasar el espesor medio de una capa pictórica no alterada alrededor de $300 \mu \mathrm{m}$. El volumen de mezcla colorante para aplicar una sola capa de pintura sobre esta fachada equivale aproximadamente a 650 litros. Determinar la cantidad exacta de pigmentos correspondiente parece difícil, ya que su masa volúmica diverge según su composición y son a menudo mezclados. Sin embargo, una estimación general nos permite calcular que la masa de materiales minerales necesaria para que los artesanos pinten únicamente la parte excavada del Frontis Norte representa entre $700 \mathrm{~kg}$ y 1 tonelada. Si tomamos en cuenta la totalidad de los murales hoy día descubiertos sobre este edificio, es fácil tomar conciencia que la cantidad de materiales necesarios a su elaboración era muy importante.

Por otro lado, una vez los ingredientes preparados (molienda de los pigmentos minerales, preparación del carbón de madera y de los coadyuvantes), tienen que ser mezclados según una receta precisa (pigmento + carga + aglutinante), y según proporciones adecuadas en función del color deseado, así como de las zonas que pintar. Esta operación necesitaba entonces la aplicación de una destreza precisa que quedó idéntica durante el tiempo y sobre cada sitio estudiado, como lo indicaron los análisis.

En paralelo a la elaboración de las mezclas colorantes, los artesanos tenían también que preparar los muros soportes. Sobre la capa de sedimento, puesta sobre el muro de adobes, debían dibujar los motivos. Podían delimitar el cuadro de la escena con cuerdecillas de algodón tensadas sobre el muro, mientras que los motivos más complejos estaban incididos a mano, según un modelo textil (Lecoq, 2006) o elaborados sobre otros soportes como adobes (Morales, Sólorzano, Asmat, 1998; Morales, 2003). La realización de estos dibujos preparatorios exigía pues personas calificadas, obedeciendo a códigos visuales e iconográficos precisos. Si el adorno consistía en un relieve, era luego necesario modelar las partes prominentes, por modelaje o escisión de materia (Morales, Sólorzano, Asmat, 1998).

La última etapa de elaboración de un mural correspondía a la aplicación de la mezcla colorante sobre los muros ya preparados. El artesano debía entonces respetar un «código de color» preestablecido con una significación precisa.

Una vez acabados, algunos murales fueron el objeto de un mantenimiento regular. En efecto pudimos observar, gracias a la microscopía, varias capas pictóricas 
superpuestas, en particular sobre el Frontis Norte del Edificio A de la huaca de la Luna, donde pudimos notar hasta 23 repintados sucesivos. Esta observación tiende entonces a mostrar que la elaboración de un mural no correspondía a un evento episódico pero a una actividad que se desarrollaba en el tiempo, necesitando un trabajo e intervenciones regulares.

Todos los análisis permitieron precisar algunas etapas de la cadena operativa seguida por los artesanos para elaborar un mural. Además, los datos adquiridos en cuanto a la ejecución de cada una de las fases de la gama de fabricación, permiten argumentar que la realización de un panel pintado correspondía a una verdadera actividad artesanal, con diferentes tareas ejecutadas por artesanos suficientemente numerosos y calificados, los cuales debían después estar disponibles para un mantenimiento o modificaciones. La diversidad y la importancia de cada operación manual nos incita a suponer que existía una repartición de las tareas entre los protagonistas. Por otro lado, parece evidente que algunas actividades necesitaban un grado de especialización y una formación particular. En efecto, el artesano encargado de la realización del dibujo preparatorio sobre el soporte tenía muy probablemente más responsabilidades que el obrero encargado de la molienda de las materias primas por ejemplo.

Estas conclusiones nos permiten proponer la hipótesis según la cual los obreros que participaban a la elaboración de las pinturas murales de los templos fueron suficientemente numerosos para responder a las diferentes obligaciones de la cadena operativa, y fueron agrupados en una verdadera clase artesanal. Esta estaba muy probablemente jerarquizada y reunía artesanos con un grado de especialización variable. Por fin, hemos mostrado que la actividad de elaboración de un mural fue indisociable de la clase gobernante. Es pues importante preguntarse sobre las relaciones que existían entre estos artesanos y la élite.

\section{2. 3. La artesanía pictórica y la élite}

Las precedentes conclusiones nos permitieron proponer que los artesanos pintores fueron reunidos en una misma clase artesanal, destinada a producir un bien, paneles murales, reservados a la clase gobernante que les utilizaban como vector ideológico. Es evidente que esta actividad estaba íntimamente ligada a la élite que era la beneficiaria pero también controlaba su producción (Costin \& Hagstrum, 1995; Bawden, 1996; DeMarrais et al., 1996; Shimada, 2001; Bernier, 2008; Fraresso, 2008). En efecto, mostramos que elaborar un mural requería varias tareas con más o menos responsabilidades, lo que permitía inferir una jerarquización social de esta clase artesanal. Por otra parte, podemos suponer que las diferentes etapas de la cadena operativa fueron supervisadas por personajes jerárquicamente más importantes, perteneciendo quizás ellos mismos a la clase gobernante (Chapdelaine, 2001; Shimada, 2001). Podemos también proponer que algunos artesanos con un alto grado de especialización, podían ser relacionados con la élite, lo que ya se supone en otros sectores artesanales como la cerámica o la metalurgia (Chapdelaine, 2001; Bernier, 2008; Fraresso, 2008; Rengifo \& Rojas, 2008). 
Además, Max Uhle, quien excavó la Plataforma Uhle en Moche entre 1899 y 1900, menciona el descubrimiento de una tumba (Tumba 23) que podría confortar nuestra hipótesis. En efecto, cataloga una serie de herramientas que hubieran podido corresponder a pilones para moler los pigmentos, asociadas a un individuo que ocuparía, en este caso, una función de «maestro pintor» (Morales, 2000b). Ahora bien, esta Plataforma Uhle constituye un espacio funerario reservado a las clases gobernantes de la sociedad mochica (Pimentel \& Álvarez, 2000), demostrando que algunos artesanos pintores estarían ligados a la élite. Sin embargo, tenemos pocos datos sobre este entierro, y las excavaciones ulteriores en este sector (Chauchat \& Gutiérrez, 2006) no revelaron vestigios similares.

\section{2. 4. ¿indicios de talleres?}

De esta manera, si los artesanos pintores son reunidos en una clase artesanal, y que estos especialistas son ligados a la élite, podemos proyectar que trabajaban en talleres especializados, comparables a los de las ceramistas, metalurgistas o tejedores por ejemplo (Chapdelaine, 2001; Shimada, 2001; Fraresso, 2008; Rengifo \& Rojas, 2008). Arqueológicamente, esta producción especializada debería traducirse por una concentración importante de vestigios directamente correlacionados a esta activad, indicadores de la presencia de un taller artesanal (Bernier, 2008).

Ahora bien, en el centro urbano del sitio de Moche, un conjunto arquitectónico excavado en 1995 (Chapdelaine et al., 1997), y luego en 1998 y 1999 (Chapdelaine et al., 2003) entregó varios vestigios cuya interpretación podría confortar nuestra hipótesis. En efecto, en este complejo arquitectónico, llamado CA5 (fig. 6), ubicado a $300 \mathrm{~m}$ al suroeste de la huaca de la Luna, el material descubierto tendería a mostrar que pigmentos y mezclas colorantes hubieran sido preparados en varios espacios específicos.

En efecto, podemos notar artefactos en relación con la molienda de los materiales colorantes (morteros y pilones) y su almacenaje (jarras domésticas con las paredes internas cubiertas de sustancia colorada). Ubicado al pie de la huaca de la Luna, cerca de los otros talleres, podemos suponer que este espacio hubiera sido la sede de algunas actividades artesanales en relación con la preparación de pigmentos, quizás asociadas con la elaboración de los murales. En efecto, hemos mostrado que una de las primeras etapas de la gama de fabricación de un mural consistía en la molienda de las materias primas minerales. Ahora bien, la cantidad de pigmento necesaria era muy importante, exigiendo pues una mano de obra suficiente y estructuras de trabajo adaptadas. El descubrimiento, en este sector de una gran cantidad de morteros y pilones (algunos cubiertos de pigmentos), tendería a indicar que esta etapa de fabricación hubiera podido ocurrir en una estructura y con herramientas similares.

Estos primeros indicios arqueológicos convergen para demostrar que este sector arquitectónico fue posiblemente en relación con una actividad artesanal, quizás la artesanía pictórica. Sin embargo, se trata de unas hipótesis. El análisis físico químico 
Pigmentos y tecnología artística mochicas: nueva aproximación para comprender la organización social

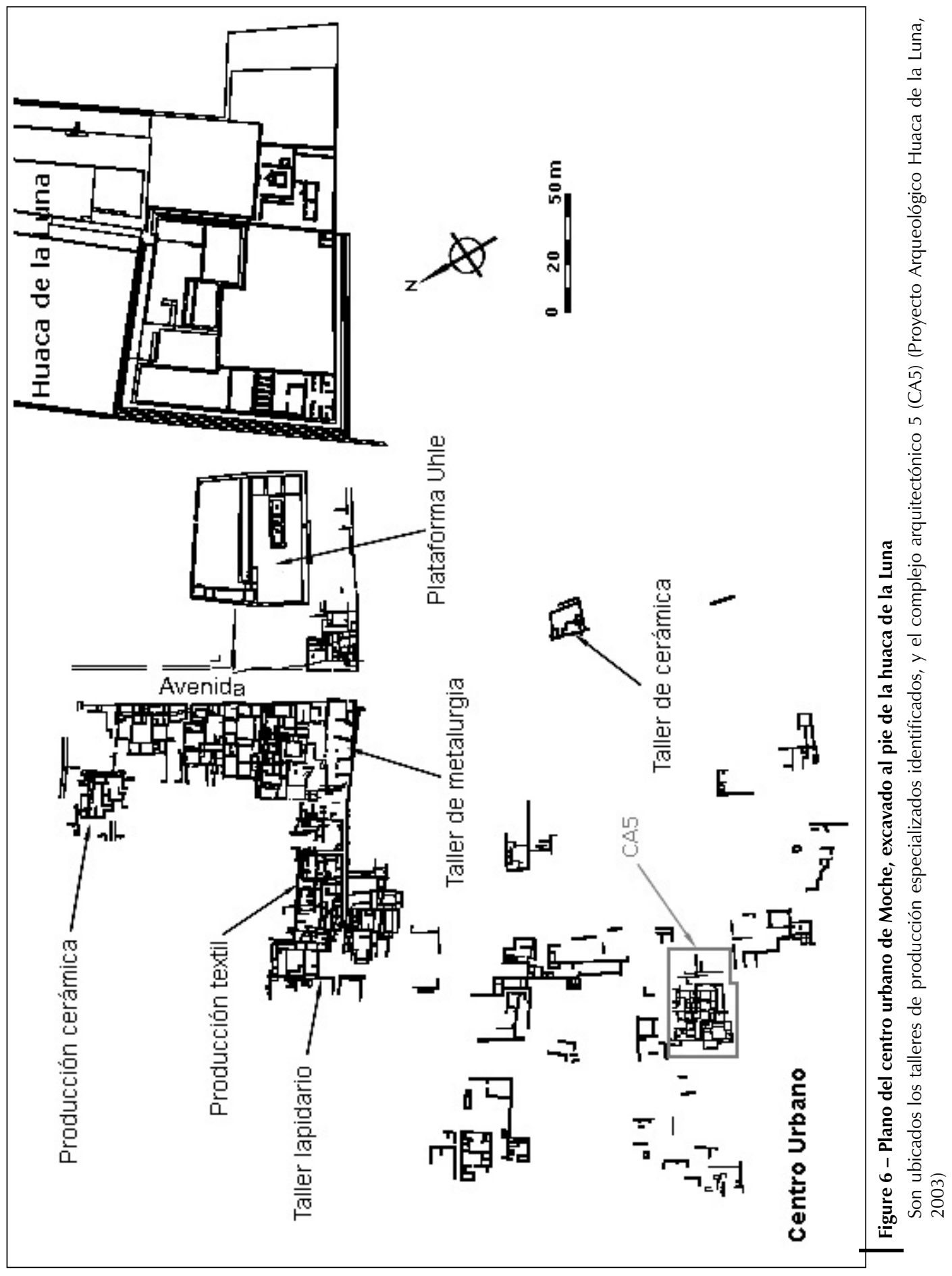


de las herramientas y de los depósitos de materias colorantes permitiría obtener datos importantes para confortar o no estas conjeturas. Además, la excavación completa de la parte este de este complejo, que fue simplemente sondeada, podría dar datos complementarios útiles a la interpretación de la función de esta zona del centro urbano de Moche.

Por fin, algunas investigaciones sobre los engobes rojos y blancos sobre cerámicas descubiertas en Moche, indicaron que los pigmentos empleados para realizar estas pinturas (Chapdelaine, Mineau \& Uceda, 1997) eran idénticos a los utilizados en el arte mural. Por eso, es oportuno preguntarse si la preparación de los pigmentos en el CA5 no fue también destinada a la elaboración de las pinturas cerámicas lo que sugería una interconexión entre estas dos actividades artesanales.

\section{CONCLUSIONES}

El estudio arqueométrico desarrollado sobre el arte mural mochica permitió sacar conclusiones no solamente sobre los materiales y las técnicas pero también más generalmente sobre la identidad social del artesano pintor mochica. En efecto, la puesta en evidencia de un conocimiento técnico, para elaborar un mural, que se transmite de una generación a otra de artesanos en un mismo sitio, pero también sobre todo el territorio, nos permitió proponer que los artesanos pintores, dotados de una experiencia y de conocimientos específicos, fueron agrupados en una verdadera clase artesanal. Por otro lado, la producción de este trabajo es destinada a un grupo de «consumidores» seleccionados y restringidos, que corresponde a la élite, para crear un producto simbólico que sirve y materializa su poder político. Esta observación tiende entonces a mostrar que esta actividad «ligada» a la clase gobernante, fue muy probablemente «especializada».

Aceptando que estos artesanos estuvieran reunidos en una clase artesanal especializada, hemos mostrado que existía probablemente una repartición de las tareas, según la cadena operativa caracterizada, exigiendo un grado de especialización más o menos importante de cada uno de los protagonistas. Esta observación permitió proponer que esta unidad de producción fue jerarquizada, precisamente con respeto a esta distribución de las operaciones, algunas necesitando una formación y responsabilidades más considerables que otras.

Pudimos también proponer que las diferentes etapas de la gama de producción podían ser supervisadas por personajes jerárquicamente más importantes. La garantía de este control de actividad por individuos con una autoridad más marcada, nos permitió sugerir que algunos artesanos podían ser estrechamente asociados a la clase gobernante y quizás también pertenecer a la élite.

Por fin, las estimaciones en cuanto a las cantidades de materiales minerales necesarios a la elaboración de un mural, así como la identificación de repintados sucesivos sobre varios paneles, dejan pensar que esta actividad artesanal consistía en un trabajo regular y no puntual. Sin embargo, es posible considerar que algunos artesanos estaban también asociados a otras clases artesanales lo que podría reducir la importancia numérica de esta categoría social. 
Entonces, aunque estas interpretaciones sigan siendo unas hipótesis, permiten entender que la elaboración de un mural atestigua una producción organizada y relativamente compleja, argumentando el interés de proseguir las investigaciones en este tema, que sea en laboratorio o en el campo. Estas conclusiones demuestran también el alcance del estudio arqueométrico que nos permitió trabajar sobre la tecnología artística mochica y también sacar interpretaciones más generales en cuanto a la organización social y territorial de esta actividad artesanal especial.

\section{Agradecimientos}

Quería agradecer especialmente a los directores del Proyecto Arqueológico Huaca de la Luna, los Profesores Santiago Uceda y Ricardo Morales. Sin ellos este trabajo nunca hubiera existido. Agradezco también sinceramente al Profesor Eric Taladoire, mi director de tesis de doctorado, quien me ayudó durante estos cuatro años de investigaciones. Por fin, quiero agradecer al «Centre de Recherche et de Restauration des Musées de France» donde pude trabajar en las mejores condiciones.

\section{Referencias citadas}

ALVA W., 2004 - Sipán, Descubrimiento e Investigación (W. Alva, ed.); Lima: Quebecor World Perú.

BAWDEN, G., 1996 - The Moche, The peoples of America, 375 pp.; Cambridge: Blackwell Publishers.

BERNIER, H., 2008 - Especialización artesanal en el sitio Huacas de Moche: Contextos de producción y función sociopolítica. In: arqueología Mochica: nuevos enfoques (L. J. Castillo, H. Bernier, J. Rucabado \& G. Lockard, eds.): 33-51; Lima: Instituto Francés de Estudios Andinos, Pontificia Universidad Católica del Perú. Actas del Primer Congreso Internacional de Jóvenes Investigadores sobre la Cultura Mochica (Pontificia Universidad Católica del Perú, Dumbarton Oaks y Museo Larco, 4 y 5 de agosto de 2004).

BONAVIA, D., 1985 - Mural painting in ancient Peru, 224 pp.: Bloomington: Indiana University Press.

BOULVAIN, F., 2004 - Éléments de sédimentologie et de pétrologie sédimentaire; Liège: Université de Liège, Faculté des Sciences, Département de Géologie, Unité de Pétrologie sédimentaire. Cours de pétrologie sédimentaire.

BOURGÈS, A., 1998 - Peintures murales mochicas, Huaca de la Luna, Trujillo, Pérou; Bordeaux: CRP2A, Université Michel de Montaigne-Bordeaux III. Maîtrise de Physique Appliquée à l'Archéologie.

BOURGET, S., 1994 - Bestiaire sacré et flore magique : Écologie rituelle de l'iconographie de la culture Mochica, côte nord du Pérou; Montreal: Université de Montréal. Thèse de doctorat. 
BOURGET, S., 2003 - Somos diferentes: dinámica ocupacional del sitio del Castillo de Huancaco, Valle de Virú. In: Moche hacia el final del Milenio, Tomo 1: 245-267; Trujillo: Pontificia Universidad Católica del Perú, Universidad Nacional de Trujillo. Actas del Segundo Coloquio sobre la Cultura Moche, Trujillo, 1-7 de agosto de 1999.

CAMPANA DELGADO, C. \& MORALES GAMARRA, R., 1997 - Historia de una deidad mochica, 120 pp.; Lima: A \& B S.A.

CASTILLO BUTTERS, L. J. \& UCEDA CASTILLO, S., ms. - The Mochicas of North Coastal Peru. In: Handbook of South American Archaeology (H. Silverman \& W. Isbell): Chapter $\mathrm{X}$; American Journal of Archaeology, Archaeological Institute of America.

CHAPDELAINE, C., 2001 - The Growing power of Moche Urban Class. In: Moche Art and Archaeology in Ancient Peru: 69-88; New York: Yale University Press, National Gallery of Art. Studies in the History of Art 63.

CHAPDELAINE, C., BERNIER, H. \& PIMENTEL, V., 2003 - Investigaciones en la Zona Urbana Moche, temporadas 1998 y 1999. In: Investigaciones en la Huaca de la Luna 1998-1999 (S. Uceda, E. Mujica \& R. Morales, eds.): 123-201; Trujillo: Universidad nacional de Trujillo, Facultad de Ciencias Sociales.

CHAPDELAINE, C., KENNEDY, G. \& UCEDA CASTILLO, S., 1995 - Activación neutrónica en el estudio de la producción local de la cerámica ritual en el sitio de Moche, Perú. Bulletin de I'Institut Français d'Études Andines, 24 (2): 183-212.

CHAPDELAINE, C., KENNEDY, G. \& UCEDA CASTILLO, S., 2001 - Neutron activation analysis of metal artefacts from the Moche site, north coast of Peru. Archaeometry, Vol. 43, part 3: 373-393; Blackwell Publishers.

CHAPDELAINE, C., MINEAU, R. \& UCEDA CASTILLO, S., 1997 - Estudio de los pigmentos de la cerámica ceremonial moche con la ayuda de un microscopio electrónico de barrido. Bulletin de I'Institut Français d'Études Andines, 26 (2): 229-245.

CHAPDELAINE, C., UCEDA, S., MOYA, M., JAUREGUI, C. \& UCEDA, C., 1997 - Los complejos arquitectónicos urbanos de Moche. In: Investigaciones en la Huaca de la Luna 1995 (S. Uceda, E. Mujica \& R. Morales, eds.): 71-92; Trujillo: Universidad nacional de Trujillo, Facultad de Ciencias Sociales.

CHAUCHAT, C. \& GUTIÉRREZ, B., 2006 - Excavaciones en el conjunto arquitectónico 18 (Plataforma Uhle) durante las temporadas 1999 y 2000. In: Investigaciones en la Huaca de la Luna 2000 (S. Uceda, E. Mujica \& R. Morales, eds.): 105-147; Trujillo: Universidad Nacional de Trujillo, Facultad de Ciencias Sociales.

COSTIN, C. L. \& HAGSTRUM, M. B., 1995 - Standardization, labor investment, skill, and the organization of ceramic production in Late Prehispanic Highland Peru. American Antiquity, Vol. 60, n. ${ }^{\circ}$ 4: 619-639; Society for American Archaeology.

DEMARRAIS, E., CASTILLO BUTTERS, L. J. \& EARLE, T., 1996 - Ideology, Materialization, and Power Strategies. Current Anthropology, Vol. 37, n. ${ }^{\circ}$ 1: 15-31; Chicago: University of Chicago Press.

DONNAN, C. B., 1978 - Moche art of Peru, Pre-Columbian symbolic communication, 205 pp.; Los Angeles: University of California-Los Angeles. Museum of Cultural History.

FRANCO JORDÁN, R., GÁLVEZ MORA, C. \& VÁSQUEZ SÁNCHEZ, S., 1994 - Arquitectura y decoración mochica en la Huaca Cao Viejo, Complejo El Brujo: resultados preliminares. In: Moche, Propuestas y perspectivas (S. Uceda \& E. Mujica, eds.): 147-181; Universidad Nacional de la Libertad de Trujillo. Actas del Primer Coloquio sobre la Cultura Moche, Trujillo, 12 al 16 de abril de 1993. 
Pigmentos y tecnología artística mochicas: nueva aproximación para comprender la organización social

FRANCO JORDÁN, R., GÁLVEZ MORA, C. \& VÁSQUEZ SÁNCHEZ, S., 2003 - Modelos, función y cronología en la Huaca Cao Viejo, complejo El Brujo. Moche hacia el final del Milenio, Tomo 2: 125-178; Trujillo: Pontificia Universidad Católica del Perú, Universidad Nacional de Trujillo. Actas del Segundo Coloquio sobre la Cultura Moche, Trujillo, 1-7 de agosto de 1999.

FRARESSO, C., 2008 - El «sistema técnico» de la metalurgia de transformación en la cultura Mochica: nuevas perspectivas. In: arqueología Mochica: nuevos enfoques (L. J. Castillo, H. Bernier, J. Rucabado \& G. Lockard, eds.): 153-185; Lima: Instituto Francés de Estudios Andinos, Pontificia Universidad Católica del Perú. Actas del Primer Congreso Internacional de Jóvenes Investigadores sobre la Cultura Mochica (Pontificia Universidad Católica del Perú, Dumbarton Oaks y Museo Larco, 4 y 5 de agosto de 2004).

HORTOLÀ, P., 2002 - Red Blood Cell Haemotaphonomy of Experimental Human Bloodstains on Techno-Prehistoric Lithic Raw Materials. Journal of archaeological Science, n. ${ }^{\circ}$ 29: 733-739; Academic Press, Elsevier B. V.

KAKOULLI, I., 1997 - Materials and techniques of the pre-Hispanic paintings at El Brujo, Huaca Cao Viejo, Peru; Oxford: University of Oxford: Smithsonian Institution, Research Laboratory for Archaeology and the History of Art. D. Phil. Student.

LARCO HOYLE, R., 2001 - Los Mochicas, xxix + $333+350$ pp.; Lima: Museo Arqueológico Larco Herrera, Fundación Telefónica.

LECOQ, P., 2006 - Choqek'iraw, le site inca des lamas sacrés. Pour la Science, n. ${ }^{\circ}$ 343: 6673; París: Édition française du Scientific American.

MORALES GAMARRA, R., 2000a - Atuendo ceremonial moche: excepcional hallazgo en la Huaca de la Luna. Iconos: 49-53, 62-63. Revista peruana de conservación, Arte y arqueología.

MORALES GAMARRA, R., 2000b - Max Uhle: Murales y materiales pictóricos en las Huacas de Moche (1899-1900). In: Investigaciones en la Huaca de la Luna 1997 (S. Uceda, E. Mujica \& R. Morales, eds.): 235-266; Trujillo: Universidad nacional de Trujillo, Facultad de Ciencias Sociales.

MORALES GAMARRA, R., 2003 - Iconografía litúrgica y contexto arquitectónico en Huaca de la Luna, Valle de Moche. Moche hacia el final del Milenio, Tomo 1: 425-476; Lima: Instituto Francés de Estudios Andinos, Pontificia Universidad Católica del Perú. Actas del Primer Congreso Internacional de Jóvenes Investigadores sobre la Cultura Mochica (Pontificia Universidad Católica del Perú, Dumbarton Oaks y Museo Larco, 4 y 5 de agosto de 2004).

MORALESGAMARRA, R., SOLÓRZANO, J. \& ASMAT, M., 1998-Superficies arquitectónicas: tipología, tecnología y materiales. In: Investigaciones en la Huaca de la Luna 1996 (S. Uceda, E. Mujica \& R. Morales, eds.): 211-219; Trujillo: Universidad nacional de Trujillo, Facultad de Ciencias Sociales.

MORALES GAMARRA, R., ASMAT, M., SOLÓRZANO, J., ASMAT, M., SÁNCHEZ, L. \& GIL, D., 2006 - Frontis Norte. In: Proyecto Arqueológico Huaca de la Luna. Informe técnico 2005 (S. Uceda \& R. Morales, eds.): 371-400; Trujillo: Universidad Nacional de Trujillo, Facultad de Ciencias Sociales.

OTTE, M., 2005 - Arts Préhistoriques, L'articulation du langage, 183 pp. ; Bruxelles: Éditions De Boeck Université.

PETERSEN, G., 1970 - Minería y metalurgia en el Antiguo Perú, iv + 140 pp.; Lima: Museo Nacional de Antropología y arqueología, Publicaciones del Instituto de Investigaciones Antropológicas, Pueblo Libre. 
PIMENTEL, V. \& ÁLVAREZ, G., 2000 - Relieves policromos en la plataforma funeraria Uhle. In: Investigaciones en la Huaca de la Luna 1997 (S. Uceda, E. Mujica \& R. Morales, eds.): 181-203; Trujillo: Universidad Nacional de Trujillo, Facultad de Ciencias Sociales.

RENGIFO CHUNGA, C. E. \& ROJAS VEGA, C. G., 2008 - Talleres especializados en el conjunto arqueológico Huacas de Moche: el carácter de los especialistas y su producción. In: Arqueología Mochica: nuevos enfoques (L. J. Castillo, H. Bernier, J. Rucabado \& G. Lockard, eds.): 325-339; Lima: Instituto Francés de Estudios Andinos, Pontificia Universidad Católica del Perú. Actas del Primer Congreso Internacional de Jóvenes Investigadores sobre la Cultura Mochica (Pontificia Universidad Católica del Perú, Dumbarton Oaks y Museo Larco, 4 y 5 de agosto de 2004).

ROQUE, C., VARTANIAN, E., GUIBERT, P., SCHVOERER, M., LÉVINE, D., ALVA, W. \& JUGNER, H., 2002 - Recherche chronologique sur la culture Mochica du Pérou : Datation de la Tombe du Prêtre de Sipán par thermoluminescence (TL) et par radiocarbone. Journal de la Société des Américanistes, Tome 88: 227-243; París.

SCHAEDEL, R. P., 1951 - Mochica Murals at Pañamarca, Archaeology, Vol. 4, n. ${ }^{\circ}$ 3: 145 154; Long Island NY, USA: Archaeological Institute of America.

SCOTT, D. A., DOUGHTY, D. H. \& DONNAN, C. B., 1998 - Moche wallpainting pigments from La Mina, Jequetepeque, Peru, Studies in conservation, Vol. 43, n. ${ }^{\circ}$ 3: 177-182; London: The International Institute for Conservation of Historic and Artistic Works.

SHIMADA, I., 2001 - Late Moche Urban Craft Production: A First Approximation. In: Moche Art and Archaeology in Ancient Peru: 177-207; Nueva York: Yale University Press, National Gallery of Art. Studies in the History of Art 63.

SWANN, C. P., CASPI, S. \& CARLSON, J., 1999 - Six stirrup handled Moche ceramic vessels from pre-Colombian Peru: a technical study applying PIXE spectrometry. Nuclear Instruments and Methods in Physics Research Section B: Beam Interactions with Materials and Atoms, Vol. 150, Issues 1-4: 571-575; Elsevier B. V.

TUFINIO, M., 2006 - Excavaciones en el Frontis Norte y Plaza 1 de la Huaca de la Luna. In: Proyecto Arqueológico Huaca de la Luna. Informe técnico 2005 (S. Uceda \& R. Morales, eds.): 41-77; Trujillo: Universidad Nacional de Trujillo, Facultad de Ciencias Sociales. Ms.

UCEDA CASTILLO, S. \& TUFINIO CULQUICHICÓN, M., 2003 - El complejo arquitectónico religioso Moche de Huaca de la Luna: una aproximación a su dinámica ocupacional. In: Moche hacia el final del Milenio, Tomo 2: 179-228; Trujillo: Universidad Nacional de Trujillo, Pontificia Universidad Católica del Perú, Fondo Editorial 2003. Actas del Segundo Coloquio sobre la Cultura Moche, Trujillo, 1-7 de agosto de 1999.

VERGUEZ, A. \& HUISMAN, D., 1990 - L'art. In: Cours de Philosophie, Chapitre 15: 333 358; París: Éditions Nathan.

WRIGHT, V., 2002 - Colorants, Chromogènes et supports des reliefs polychromes de la Huaca de la Luna, Trujillo, Pérou. Bordeaux: Université Michel de Montaigne Bordeaux III. Maîtrise de Physique Appliquée à I'Archéologie, CRP2A.

WRIGHT, V., 2005 - Analyses préliminaires de caractérisation de supports et de pigments de reliefs polychromes, Huaca de la Luna, Trujillo, Pérou. In : De I'Altiplano mexicain à la Patagonie (É. taladoire, ed.): 255-261; París: British Archaeological Reports, Archaeopres. Monographs in American Archaeology 16, Travaux et recherches à I'Université de Paris 1. 